\title{
A fully coupled thermal-hydraulic-mechanical model with two-phase flow for coalbed methane extraction
}

\author{
Sheng $\mathrm{Li}^{1,2,3}$, Chaojun Fan ${ }^{1,2,3, *}$, Jun Han ${ }^{1}$, Mingkun Luo ${ }^{1,2,3}$, Zhenhua Yang ${ }^{1}$, Huijie Bi ${ }^{1}$ \\ (1.College of Mining engineering, Liaoning Technical University, Fuxin, Liaoning 123000, China; 2. State Key \\ Laboratory for GeoMechanics and Deep Underground Engineering, China University of Mining \& Technology, \\ Xuzhou, Jiangsu 221116, China; 3. State Key Laboratory of Coal Resources and Safe Mining, China University of \\ Mining \& Technology, Xuzhou, Jiangsu 221116, China)
}

*Corresponding author. Tel.: +86-15134012396.

E-mail: chaojunfan@139.com.

First author.E-mail: 13941811946@139.com. 
Abstract: Although the interaction of gas and coal has been comprehensively investigated in coalbed methane (CBM) extraction process, fewer scholars have taken the effect of temperature and groundwater into account, which brought a large deviation for CBM extraction design. In this study, a fully coupled thermal-hydraulic-mechanical model (THM) including coal deformation, gas seepage, water seepage, and thermal transport governing equations is developed and solved using the finite element (FE) method. The coal mass is simplified as a dual-porosity and single-permeability media while CBM migration is considered as a tandem process of desorption, diffusion and seepage. The dynamic evolution model of permeability serving as the coupled term for THM model is developed under the combined impact of stress, water pressure, gas pressure, gas adsorption/desorption and temperature. The proposed model is first verified by showing that the modeled gas production rate and water production rate match reasonably with the in-situ measured ones. Different coupled models for CBM extraction were comparatively analyzed by accomplishing a series of simulations. It is found that the gas production rate of models ignored water effect monotonously reduces over time; while the model considered water effect rises at beginning and then gradually reduces. The model ignored water effect will overestimate gas production, and the model ignored thermal effect will underestimate gas production, particularly coal seam contains considerable amount of water. The evolution of permeability is the competition result of two opposite effects: the matrix shrinkage effect caused by temperature reduction, the matrix swelling effect caused by gas pressure decrease and methane adsorption increase. A rising permeability resulted from the integrative action of both lower reservoir temperature and pressure during CBM extraction is observed. The impact of initial water saturation on gas production can not be ignored in the whole extraction process, especially during the water drainage period. Gas production rate of CBM well decreases with initial reservoir temperature, initial water saturation and Langmuir volume constant, while increases with the Klinkenberg factor. Permeability rate increases with initial water saturation and Klinkenberg factor, however decreases with initial reservoir temperature. As Langmuir volume constant increases, the peaking value of gas production rate increases and delays. The Klinkenberg effect promotes coalbed methane migration significantly, ignoring which will underestimate the gas production, and the impact of Klinkenberg effect gradually increases with the drop of gas pressure.

Key words: CBM extraction, thermal-hydraulic-mechanical coupled model (THM), gas-water two-phase flow, permeability evolution, physical factors, numerical simulation 


\section{Introduction}

Coalbed methane (CBM) as a kind of clean and unconventional natural gas, is an important source of energy (Pashin, 1998; Gentzis, et al., 2008; Palmer, 2010; Wang, et al., 2014), and is also a valuable by-product from $\mathrm{CO}_{2}$ geological sequestration in coal seam for solving the problem of global warming (Wu et al., 2011; Zhou et al., 2012; Kumar et al., 2015; Sayyafzadeh et al., 2015; Zhang et al., 2016). Meanwhile, methane (the main component of coal mine gas) is one of the most serious threat to coal mine safety, for example, the gas explosion and gas outburst often occur during the process of mining operations (Xia et al., 2014; Aguado et al., 2007; Wold et al., 2008; Sobczyk, 2011; Han et al., 2011; Sobczyk, 2014). After carbon dioxide, coalbed methane has the second greatest radiative forcing among the long-lived greenhouse gases and its emission will cause environmental pollution (Gunter et al., 1997; Cheng et al., 2011; Karacan et al., 2011). In these regards, CBM extraction is the principal and key means for the disaster and pollution prevention and the energy supply (Zhou et al., 2014). Hence, the improved solution for CBM extraction such as a reasonable and accurate mathematical model is much significant.

The coal seam, characterized by a typical dual-porosity system with micro-porous matrix and macro-porous cleats/fractures containing free and adsorbed methane, is both the source and the reservoir for CBM (Harpalani et al., 1990; Xia et al., 2015). The interaction of methane and coal seam in CBM extraction process has been comprehensively investigated (Zhao et al., 2004; Cui and Bustin 2005; Pan and Connell, 2007; Zhang et al., 2008; Durucan et al., 2009; Liu et al., 2011; An et al. 2013; Wang et al. 2013), and many gas-solid coupling models for CBM extraction were established. Zhao et al. (2004) considered that the changes of in-situ stress and gas pressure can change the effective stress of coal and increased effective stress acts to reduce the porosity and permeability, by this, they developed a nonlinear coupled mathematical model of solid deformation and gas seepage without considered methane desorption swelling. Harpalani et al. (1997) proposed a theoretical model to describe adsorption-induced coal swelling at adsorption and strain equilibrium. Connell (2009) developed a coupled numerical model for gas extraction in coal seam reservoirs, and considered that the permeability in coal seam is sensitive to stress, pore pressure changes and the gas desorption /adsorption induced coal matrix shrink/swell. Xia et al. (2014) proposed a coupled compositional model of coal deformation, coal gas flow and transport, and air flow in coal seams to better understand the processes and coal gas-air mixing mechanisms during pre-mining coal seem gas drainage. However, the dependence of gas pressure and gas desorption on gas permeability in porous media, so called Klinkenberg effect, is significant to gas flow (Klinkenberg, 1941; Zhu et al., 2007). Liu et al. (2014) considered that the effective stress laws for multi-porosity media was more suitable for CBM reservoirs and proposed a coupled gas flow and coal deformation model with the Klinkenberg effect. The gas-solid coupled models established by Hu et al. (2009) and Wang et al. (2014) also taken the Klinkenberg effect and the influence of gas adsorption/desorption induced coal deformation into account.

As a matter of fact, coal seam contains large amounts of water coexisting with methane, due to the form of CBM reservoir needs stable hydrodynamic conditions (Han et al., 2010; Morad, 2012). The complex coupling process of $\mathrm{CBM}$ extraction involves the interaction of methane, groundwater, coal and temperature, and links them together through dominant mechanisms including coal deformation, methane desorption, diffusion and seepage, water seepage and energy transport(Zhu et al., 2011; Xu et al., 2014). The existence of water in coal seam reduces the gas relative permeability by occupying the channels of methane migration; meanwhile, water also has 
effective stress effect on coal skeleton (Clarkson et al., 2011; Chen et al., 2014; Clarkson et al., 2015; Salmachi et al., 2015). In this regard, Rutqvist et al. (2002) presented a thermal-hydraulic-mechanical coupled model to analysis multiphase fluid flow, heat transfer, and deformation in porous and fractured rock by jointly executing the TOUGH2 and FLAC3D computer codes, but did not take gas adsorption and Klinkenberg effect into consideration. Thararoop et al. (2012) determined the relationship between the methane and water seepage through the relative permeability and established a coupled model without considering the thermal effect. However, the coal seam temperature variation will affect methane adsorption/desorption, force coal mass generating thermal strain and change the density, viscosity of water and methane (Clarkson et al., 1997; Crosdale et al., 2008). The thermal impact on coal-gas interactions cannot be neglected especially where the temperature is high. Gu and Chalaturnyk (2010), Zhu et al. (2011) developed a coupled model of coal deformation, gas transport and thermal transport to investigate the complex coal and gas interactions under variable temperatures. In their case, they also ignored the influence of water.

In this work, we extend previous models of coalbed methane extraction by combining coal deformation (effective stress, gas-desorption-induced shrinking and thermal-induced swelling), gas seepage, water seepage (gas-water two-phase flow), and thermal transport together, namely fully coupled thermal-hydraulic-mechanical model, to accurately predict and evaluate coalbed methane well production. Furthermore, coalbed methane extraction associated with initial water saturation, initial reservoir temperature, Langmuir volume constant and Klinkenberg factor, are quantitatively investigated through numerical simulations to better understand the methane migration rules in coal seam.

\section{Governing equations}

In the following, a set of field governing equations are defined to govern the coal deformation, the methane and water transport, the energy conduction and convection. These derivations are based on the following hypotheses (Zhang et al., 2008; Wu et al., 2010; Zhu et al., 2011; Xia et al., 2015; Liu et al., 2015; Guo et al., 2015): (1) the representative element volume (REV) within the coal seam is used for governing equations; (2) coal is a dual-porosity, single-permeability poroelastic continuum and its strains are infinitesimal;(3) the water exists and migrates only in fracture, and the methane exists and migrates in both pore and fracture, and fractures are saturated by the methane and water; (4) the methane migration in the coal seam is closely related to the pore structure and is treated as a tandem of two step process: firstly, methane diffuses from the matrix to the fractures satisfying Fick's law, secondly, methane seepages from fractures to CBM well satisfying Darcy's law, as shown in Fig. 1; (5) methane is agreed with the ideal gas state equation and adsorbs/desorbs in an instant; (6) the volume force of gas is not considered; and (7) tensile stress is positive, while pore pressure is negative. 


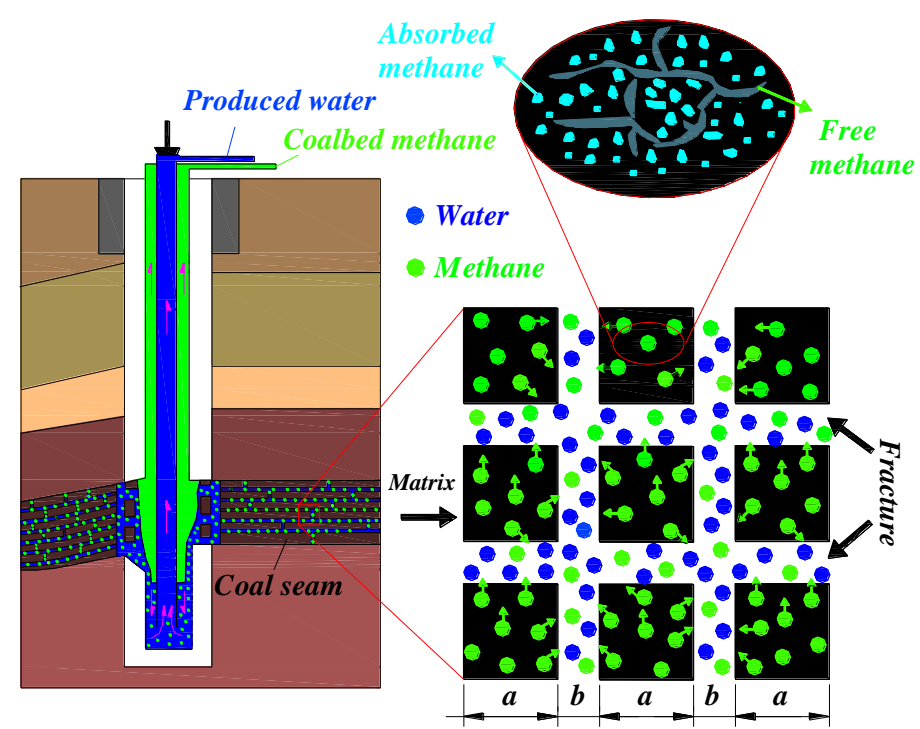

Fig. 1. Schematic of methane and water migration process during CBM extraction, where $a$ is the average length of matrix and $b$ is the average aperture of fracture.

\subsection{Governing equation of mechanical field}

By taking thermal expansion/contraction strain, pore and fracture pressure induced strain and methane desorption/adsorption induced shrinkage/swelling strain into consideration, the constitutive relations for non-isothermal coal seams can be expressed as (Zhu et al., 2011; Xia et al., 2014; Liu et al., 2015):

$$
\varepsilon_{i j}=\frac{1}{2 G} \sigma_{i j}-\left(\frac{1}{6 G}-\frac{1}{9 K}\right) \sigma_{k k} \delta_{i j}+\frac{\alpha_{T}}{3}\left(T-T_{0}\right) \delta_{i j}+\frac{\alpha_{m} p_{m}+\alpha_{f} p_{f}}{3 K} \delta_{i j}+\frac{\varepsilon_{a}}{3} \delta_{i j}
$$

Where $G=D / 2(1+v), D=1 /\left[1 / E+1 /\left(a K_{n}\right)\right], K=D / 3(1-2 v), K_{s}=E_{s} / 3(1-2 v), \varepsilon_{a}=\alpha_{s g} V_{s g}, \alpha_{m}=1-K / K_{s}$ and $\alpha_{f}=1-K /\left(a K_{n}\right) . G$ is shear modulus $(\mathrm{Pa}), K$ is bulk modulus $(\mathrm{Pa}), K_{s}$ is the skeleton bulk modulus (Pa), $K_{n}$ is the stiffness of fracture (Pa), $D$ is the effective elastic modulus (Pa), $E$ is elastic modulus $(\mathrm{Pa}), E_{s}$ is the skeleton elastic modulus $(\mathrm{Pa}), v$ is Poisson's ratio, $\alpha_{T}$ is thermal expansion coefficient $\left(\mathrm{K}^{-1}\right), T$ is temperature variable $(\mathrm{K}), T_{0}$ is initial temperature in coal seam (K), $\varepsilon_{a}$ is volumetric matrix shrinkage strain induced by methane desorption, $\alpha_{m}$ and $\alpha_{f}$ is the Biot effective stress coefficient (Biot, 1941), $\alpha_{s g}$ is the coefficient of gas adsorption induced strain $\left(\mathrm{kg} \cdot \mathrm{m}^{-3}\right), V_{s g}$ is the absorbed gas content $\left(\mathrm{m}^{3} \cdot \mathrm{kg}^{-1}\right), p_{f}$ is the mixture (containing both water and gas) pressure in fracture, $p_{m}$ is the gas pressure in matrix, $a$ is the length of the matrix, $\delta_{i j}$ is the Kronecker delta with 1 for $i=j$ and 0 for $i \neq j$.

By taking the volume average of the pressure in the mixture, fracture pressure can be defined as (Rutqvist et al., 2002):

$$
p_{f}=s_{w} p_{f w}+s_{g} p_{f g}
$$

In which $p_{f w}$ is water pressure in fracture $(\mathrm{Pa}), p_{f g}$ is gas pressure in fracture $(\mathrm{Pa}), s_{w}$ is water saturation, $s_{g}$ is gas saturation, $s_{w+} s_{g}=1$.

The absorbed gas content can be expressed as a modified Langmuir volume equation (Zhu et al., 2011): 


$$
V_{s g}=\frac{V_{L} p_{m}}{P_{L}+p_{m}} \exp \left[-\frac{d_{2}}{1+d_{1} p_{m}}\left(T-T_{t}\right)\right]
$$

Where $d_{1}$ is the pressure coefficient $\left(\mathrm{MPa}^{-1}\right), d_{2}$ is the temperature coefficient $\left(\mathrm{K}^{-1}\right), V_{L}$ is the Langmuir volume constant $\left(\mathrm{m}^{3} \cdot \mathrm{kg}^{-1}\right), p_{L}$ is the Langmuir pressure constant $(\mathrm{Pa})$, and $T$ is the temperature of coalbed $(\mathrm{K}), T_{t}$ is the reference temperature of desorption/adsorption test $(\mathrm{K})$.

The strain-displacement relation, the Cauchy formula, can be expressed as:

$$
\varepsilon_{i j}=\frac{1}{2}\left(u_{i, j}+u_{j, i}\right)
$$

Where $u_{i}(i=\mathrm{x}, \mathrm{y}, \mathrm{z})$ is displacement in the $i$-direction.

The equations of stress equilibrium relations can be defined as:

$$
\sigma_{i j, j}+f_{i}=0
$$

Where $f_{i}$ is the body force in the $i$-direction.

Combining Eqs. (1), (4) and (5), a modified Navier equation of the dual-porosity model can be derived:

$$
G u_{i, j j}+\frac{G}{1-2 v} u_{j, j i}-K \alpha_{T} \Delta T_{, i}-\alpha_{m} p_{m, i}-\alpha_{f} p_{f, i}-K \varepsilon_{a, i}+f_{i}=0
$$

\subsection{Governing equation of hydraulic field}

Coalbed methane migration in matrix is a diffusion-dominated process. Methane in coal seam is in a dynamic equilibrium state at beginning, the gas pressure in the matrix equals to the gas pressure in fracture. While the equilibrium will be broken during CBM extraction, gas adsorption pressure is higher than the gas pressure in the fracture due to the different seepage velocity in fracture and matrix, adsorbed methane of the matrix system will diffuse into the fracture system. According to the Fick's diffusion law, the methane mass conservation equation in matrix can be defined as (An et al., 2013; Xia et al., 2015):

$$
\frac{\partial m_{m}}{\partial t}=-\frac{M_{g}}{\tau R T}\left(p_{m}-p_{f g}\right)
$$

In which $m_{m}$ is methane content in matrix per unit volume $\left(\mathrm{kg} \cdot \mathrm{m}^{-3}\right), M_{g}$ is methane molar mass $\left(\mathrm{kg} \cdot \mathrm{mol}^{-1}\right), R=8.314\left(\mathrm{~J} \cdot \mathrm{mol}^{-1} \cdot \mathrm{K}^{-1}\right)$ is gas molar constant, $t$ is the time. The methane desorption time $\tau$, a characteristic time, is commonly used to approximate the diffusivity of the coal matrix and equals to the time during $63.2 \%$ of the total adsorbed methane desorbs, which can be obtained by conducting the desorption experiments with coal samples.

Methane content in matrix consisted of absorbed methane and free methane components, is defined as:

$$
m_{m}=V_{s g} \rho_{s} \frac{M_{g}}{R T_{s}} p_{s}+\phi_{m} \frac{M_{g}}{R T} p_{m}
$$

Where $V_{s g}$ is the absorbed methane content $\left(\mathrm{m}^{3} \cdot \mathrm{kg}^{-1}\right), \rho_{s}$ is the density of coal skeleton $\left(\mathrm{kg} \cdot \mathrm{m}^{-3}\right)$, $p_{s}=101(\mathrm{kPa})$ is the standard atmospheric pressure $(\mathrm{Pa}), T_{s}=273.5(\mathrm{~K})$ is temperature under standard condition, $\phi_{m}$ is the porosity in matrix.

By substituting Eq. (3) and Eq. (8) into Eq (7), the methane transport equation in matrix can be derived as:

$$
\frac{\partial}{\partial t}\left\{\frac{V_{L} p_{m}}{P_{L}+p_{m}} \exp \left[-\frac{d_{2}}{1+d_{1} p_{m}}\left(T-T_{t}\right)\right] \rho_{s} \frac{M_{g}}{R T_{s}} p_{s}+\phi_{m} \frac{M_{g}}{R T} p_{m}\right\}=-\frac{M_{g}}{\tau R T}\left(p_{m}-p_{f g}\right)
$$


After the equilibrium is broken by CBM extraction, methane in the matrix will diffuse into the fracture, in other words, matrix system is the uniformly distributed mass source for fracture system. Mass conservation equation in fracture system can be expressed as:

$$
\left\{\begin{array}{l}
\frac{\partial\left(s_{w} \phi_{f} \rho_{w}\right)}{\partial t}+\nabla \cdot\left(\rho_{w} u_{w}\right)=0 \\
\frac{\partial\left(s_{g} \phi_{f} \rho_{g}\right)}{\partial t}+\nabla \cdot\left(\rho_{g} u_{g}\right)=\left(1-\phi_{f}\right) \frac{M_{g}}{\tau R T}\left(p_{m}-p_{f g}\right)
\end{array}\right.
$$

Where $\phi_{f}$ is fracture porosity, $t$ is the time $(\mathrm{s}), u_{w}$ is velocity of water $(\mathrm{m} / \mathrm{s})$, and $u_{g}$ is the velocity of gas $\left(\mathrm{m} \cdot \mathrm{s}^{-1}\right)$.

Water density is related to temperature, which can be defined as

$$
\rho_{w}=c\left(T-T_{s}\right)+\rho_{w s}
$$

In which $c$ is temperature coefficient of water $\left(\mathrm{kg} \cdot \mathrm{m}^{-3} \cdot \mathrm{K}^{-1}\right), \rho_{w s}$ is water density under standard conditions $\left(\mathrm{kg} \cdot \mathrm{m}^{-3}\right)$.

Based on generalized Darcy's law for gas-water two-phase flow, the water and gas velocity in fracture can be defined as:

$$
\left\{\begin{array}{l}
u_{w}=-\frac{k k_{r w 0} k_{r w}}{\mu_{w}} \nabla p_{f w} \\
u_{g}=-\frac{k k_{r g 0} k_{r g}}{\mu_{g}}\left(1+\frac{b_{1}}{p_{f g}}\right) \nabla p_{f g}
\end{array}\right.
$$

Where $u_{w}$ and $u_{g}$ are water velocity and gas velocity $\left(\mathrm{m} \cdot \mathrm{s}^{-1}\right)$, respectively, $k$ is the absolute permeability of coal media $\left(\mathrm{m}^{2}\right), k_{r g}$ is the endpoint relative permeability of gas, $k_{r w 0}$ is the endpoint relative permeability of water, $k_{r w}$ and $k_{r g}$ are the relative permeability of water and gas, respectively, $\mu_{w}$ and $\mu_{g}$ are the dynamic viscosity of water and gas $(\mathrm{Pa} \cdot \mathrm{s}), b_{1}$ is Klinkenberg factor (Pa).

Corey (1954) proposed a calculative model for relative permeability using the capillary pressure curve and Xu et al., (2014) confirmed that this model can accurately reflect the positive and negative effects of coal reservoir production on the reservoir deliverability. The relative permeability of gas and water is

$$
\left\{\begin{array}{l}
k_{r w}=\left(\frac{s_{w}-s_{w r}}{1-s_{w r}}\right)^{4} \\
k_{r g}=\left[1-\left(\frac{s_{w}-s_{w r}}{1-s_{w r}-S_{g r}}\right)\right]^{2}\left[1-\left(\frac{s_{w}-s_{w r}}{1-s_{w r}}\right)^{2}\right]
\end{array}\right.
$$

Where $s_{w r}$ is the irreducible water saturation, $s_{g r}$ is the residual gas saturation.

The relation between gas pressure and water pressure is as follows:

$$
p_{f w}=p_{f g}-p_{c g w}
$$

Where $p_{c g w}$ is the capillary pressure $(\mathrm{Pa})$. 
By substituting Eqs. (11) (14) into Eq (10), the governing equations of gas and water seepage field can be derived as:

$$
\begin{gathered}
\frac{\partial}{\partial t}\left(s_{g} \phi_{f} \frac{M_{g}}{R T} p_{f g}\right)+\nabla \cdot\left[-\frac{M_{g}}{R T} \frac{k k_{r g} k_{r g}}{\mu_{g}}\left(p_{f g}+b_{1}\right) \nabla p_{f g}\right]=\left(1-\phi_{f}\right) \frac{M_{g}}{\tau R T}\left(p_{m}-p_{f g}\right) \\
\frac{\partial}{\partial t}\left\{s_{w} \phi_{f}\left[c\left(T-T_{s}\right)+\rho_{w s}\right]\right\}+\nabla \cdot\left\{-\left[c\left(T-T_{s}\right)+\rho_{w s}\right] \frac{k k_{w 0} k_{w w}}{\mu_{w}} \nabla p_{f w}\right\}=0
\end{gathered}
$$

\subsection{Governing equation of thermal field}

Due to the assumption of thermal equilibrium between the fluid and solid phases, thermal balance over an REV can be expressed in terms of a single equation neglecting the interconvertibility of thermal and mechanical energy.

The effective heat convection transfer coefficient is

$$
\eta_{e f f}=-\frac{k k_{r g} 0}{\mu_{r g}}\left(1+\frac{b_{1}}{p_{f g}}\right) \nabla p_{f g} \rho_{g} C_{g}-\frac{k k_{r w 0} k_{r w}}{\mu_{w}} \nabla p_{f w} \rho_{w} C_{w}
$$

Where $C_{g}$ and $C_{w}$ are the specific heat capacity of gas, water $\left(\mathrm{J} \cdot \mathrm{kg}^{-1} \cdot \mathrm{K}^{-1}\right)$, respectively.

We assume that solid and fluid phases are always in a state of thermal equilibrium, which can be expressed as:

$$
\frac{\partial\left[\left(\rho C_{p}\right)_{e f f} T\right]}{\partial t}+\eta_{e f f} \nabla T-\nabla \cdot\left(\lambda_{e f f} \nabla T\right)+\alpha_{T} K_{\mathrm{s}} \frac{\partial \varepsilon_{v}}{\partial t}+q_{s t} \frac{\rho_{s} \rho_{g s}}{M_{g}} \frac{\partial V_{s g}}{\partial t}=0
$$

Where $\left(\rho C_{p}\right)_{e f f}=\left(1-\phi_{f}-\phi_{m}\right) \rho_{s} C_{s}+\left(s_{g} \phi_{f}+\phi_{m}\right) \rho_{g} C_{g}+s_{w} \phi_{f} \rho_{w} C_{w}$ is the effective heat capacity; $\lambda_{\text {eff }}=\left(1-\phi_{f}-\phi_{m}\right) \lambda_{s}+\left(s_{g} \phi_{f}+\phi_{m}\right) \lambda_{g}+s_{w} \phi_{f} \lambda_{w}$ is the effective coefficient of isotropic thermal conductivity, $C_{s}$ is the specific heat capacity of coal skeleton $\left(\mathrm{J} \cdot \mathrm{kg}^{-1} \cdot \mathrm{K}^{-1}\right), \lambda_{s}, \lambda_{g}$ and $\lambda_{w}$ are heat conductivity coefficient of coal skeleton, gas and water $\left(\mathrm{W} \cdot \mathrm{m}^{-1} \cdot \mathrm{K}^{-1}\right)$, respectively, $q_{s t}$ is the isosteric heat of adsorption $\left(\mathrm{kJ} \cdot \mathrm{mol}^{-1}\right)$.

In Eq. (18), the terms on the left-hand side represent the change of internal energy, heat transfer, heat convection, the change of strain energy of coal skeleton and gas adsorption energy, respectively.

\subsection{Cross coupling}

Porosity and permeability, characterized as the key factor for coal gas migration and CBM extraction, are sensitive to the stress state and material property. According to the previous work (Palmer and Mansoori, 1998; Cui and Bustin, 2005; Zhang et al., 2008), the general porosity model can be expressed as:

$$
\phi_{m}=\frac{1}{(1+S) \phi_{m 0}}\left[\left(1+S_{0}\right) \phi_{m 0}+\alpha_{m}\left(S-S_{0}\right)\right]
$$

Where $S=\varepsilon_{v}+p_{m} / K_{s}-\alpha_{T}\left(T-T_{0}\right)-\varepsilon_{a}$ and $S_{0}=\varepsilon_{v 0}+p_{m 0} / K_{s}-\varepsilon_{a 0} . \varepsilon_{v}$ is the volumetric strain of coal, $K_{s}$ is the skeleton elastic modulus. The subscript ' 0 ' is the initial value of the corresponding variable, the similar to following.

As shown in Fig. 1, the fracture porosity can be defined as follow (Wu et al., 2010): 


$$
\phi_{f}=\phi_{f 0}\left(1+\frac{\Delta b}{b_{0}}\right)=\phi_{f 0}-\frac{3 \phi_{f 0}}{\phi_{f 0}+3 K_{f} / K}\left[\alpha_{T}\left(T-T_{0}\right)+\left(\varepsilon_{a}-\varepsilon_{a 0}\right)-\left(\varepsilon_{v}-\varepsilon_{v 0}\right)\right]
$$

Where $K_{f}$ is the modified fracture stiffness, $K_{f}=a K_{n}$.

The cubic law is used to express the relationship between permeability ratio and porosity ratio in coal seams (Palmer and Mansoori, 1998; Pan and Connell, 2007; Wu et al., 2010 b):

$$
\frac{k}{k_{0}}=\left(\frac{\phi_{f}}{\phi_{f 0}}\right)^{3}
$$

Substituting Eq. (23) into Eq. (24) yields:

$$
k=k_{0}\left\{1-\frac{3}{\phi_{f 0}+3 K_{f} / K}\left[\alpha_{T}\left(T-T_{0}\right)+\left(\varepsilon_{a}-\varepsilon_{a 0}\right)-\left(\varepsilon_{v}-\varepsilon_{v 0}\right)\right]\right\}^{3}
$$

Where $k_{0}$ is the initial permeability at the stress-free state $\left(\mathrm{m}^{2}\right)$.

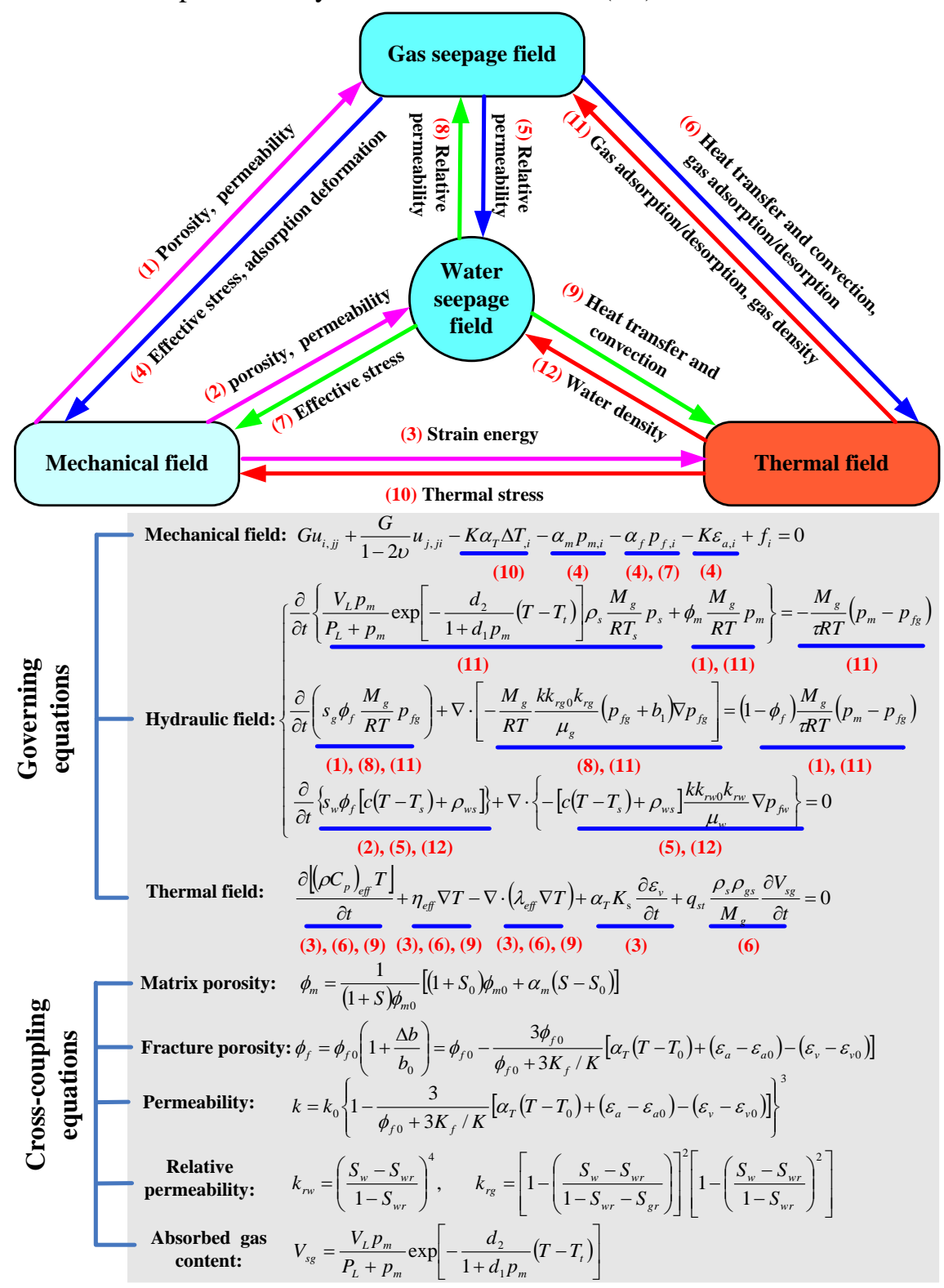

Fig. 2. Coupled interaction and the basic THM governing equations of CBM extraction (After Xia et al., 2015) 
Combining Eqs. (6), (9), (15), (16) and (18), the THM coupled mathematical model can be achieved, as shown in Fig. 2. These governing equations are nonlinear second-order partial differential equations (PDEs) in both the space and time domain and are difficult to solve theoretically due to the nonlinearity. Therefore, in the following investigation, we implement these equations into solid mechanics and PDE modules of COMSOL Multiphysics (COMSOL, 2012) to obtain numerical solution via the discrete and finite-element method.

\section{Model validation and analysis}

\subsection{Simulation case and conditions}

Qinshui Basin is located in the southeast of Shanxi Province. It is one of the earliest and most commercial valuable areas for CBM exploration and development in China (Cai, et al., 2011; Tao, et al., 2014). Fanzhuang coalbed block is a typical CBM development block in Southern Qinshui Basin, bordering on the Panzhuang and Zhengzhuang blocks (Fig. 3). The primary target zone is coal seam No. 3 in the Shanxi Formation due to its unique characteristics such as stability and thickness, high gas content and shallow burial depth. There are more than 760 vertical wells and 50 horizontal wells in Fanzhuang block since the first well was put into production in 2006. Rectangular well pattern $300 \mathrm{~m} \times 300 \mathrm{~m} \sim 500 \mathrm{~m} \times 500 \mathrm{~m}$ is widely adopted for in situ surface vertical CBM wells, with a well spacing variation of $334.67 \sim 537.98 \mathrm{~m}$. In the following sections, the practical situation of No. 1 CBM well (an unstimulated well) in production monitoring area of FanZhuang block is selected to validate the THM coupled model that we proposed.

Extraction of coalbed methane buried at $778 \mathrm{~m}$ depth is simulated using the single well method. A representative physical model of square reservoir block within $500 \mathrm{~m} \times 500 \mathrm{~m} \times 5 \mathrm{~m}$ domain developed (Fig. 4), containing a centrally located gas production well with the radius of $0.11 \mathrm{~m}$. For the physical model, the bottom boundary is fixed and a slip boundary was applied for other sides. The load from the weight of overlying strata with an average density of $2500 \mathrm{~kg} \cdot \mathrm{m}^{-3}$ is applied to the top boundary. All the external boundaries are insulated for gas, water and thermal transport. Grid generation of the domain, including 3880 elements and 47532 degrees of freedom, is done using distributed and tetrahedral mesh method.

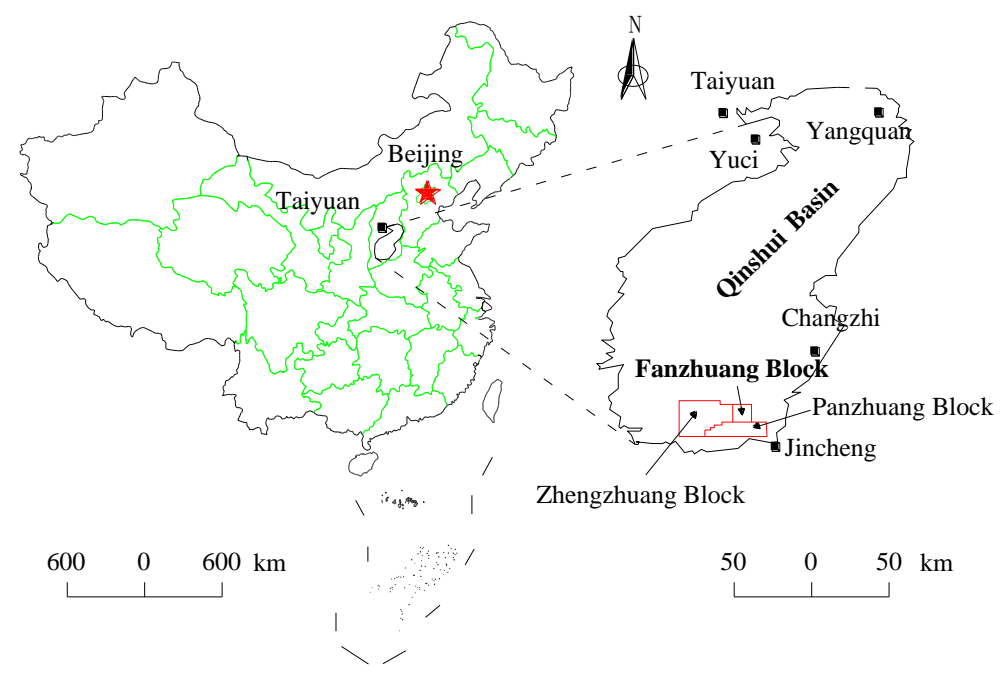

Fig. 3. Site location of Fanzhuang Block, Southern Qinshui Basin in Shanxi Province, China 
The initial gas pressure in fracture $p_{f g}$ (referred to as initial gas pressure in the following sections), temperature $T_{0}$, and permeability $k_{0}$ in the coal seam are $5.24 \mathrm{MPa}, 312.5 \mathrm{~K}, 0.514 \times 10^{-15}$ $\mathrm{m}^{2}$, respectively. Gas pressure and temperature on the CBM well wall are 0.06 MPa, 293.5 K. The temperature in CBM well is also defined as $293.5 \mathrm{~K}$ constantly, which equals to that on the well wall. Other parameters used in the numerical simulations are taken from the experimental results or literatures and listed in Table 1.

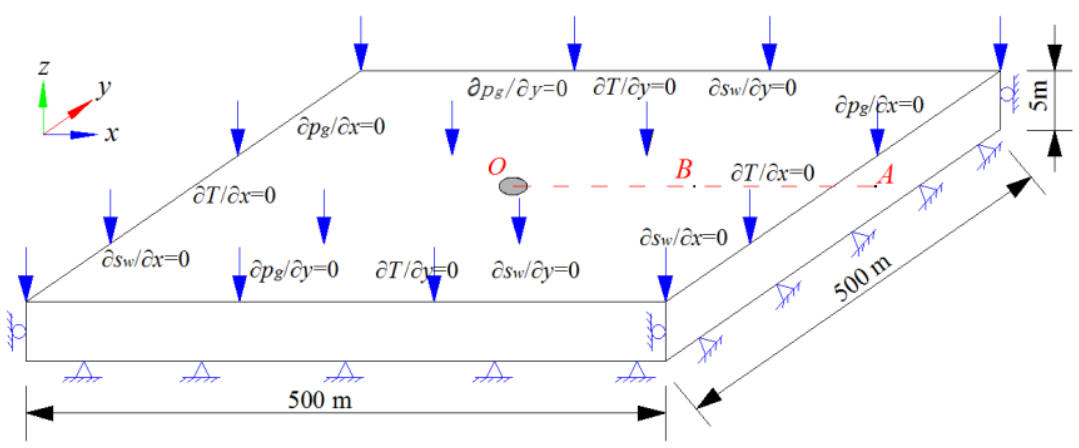

Fig. 4. Physical model for the numerical simulation, where point A locates at $(250 \mathrm{~m}, 0 \mathrm{~m}, 2.5 \mathrm{~m})$ and B locates at (125 m, $0 \mathrm{~m}, 2.5 \mathrm{~m})$.

Table 1 Related parameters used in the numerical simulation

\begin{tabular}{|c|c|c|c|c|c|}
\hline Variable & Parameter & Value & Unit & $\begin{array}{l}\text { Acquisition } \\
\text { approach }\end{array}$ & Remark \\
\hline$H$ & Buried depth & 778 & $\mathrm{~m}$ & Field data & \\
\hline$M$ & Coal seam thickness & 5.0 & $\mathrm{~m}$ & Field data & \\
\hline$p_{f g 0}$ & Initial gas pressure in fracture & 5.24 & $\mathrm{MPa}$ & Field data & \\
\hline$p_{m g 0}$ & Initial gas pressure in matrix & 5.24 & $\mathrm{MPa}$ & Field data & \\
\hline$T_{0}$ & Initial temperature in coal seam & 312.5 & $\mathrm{~K}$ & Field data & \\
\hline$k_{0}$ & $\begin{array}{l}\text { Initial permeability at the } \\
\text { stress-free state }\end{array}$ & $0.514 \times 10^{-15}$ & $\mathrm{~m}^{2}$ & Field data & \\
\hline$\tau$ & Adsorption time & 153360 & $\mathrm{~s}$ & Experiments & \\
\hline E & Young's modulus of coal & 2713 & $\mathrm{MPa}$ & Experiments & \\
\hline$E_{s}$ & Young's modulus of coal skeleton & 8469 & MPa & References & Xia et al, 2014 \\
\hline$K_{n}$ & Fracture stiffness & 4800 & MPa & References & Xia et al, 2014 \\
\hline$v$ & Poisson's ratio of coal & 0.35 & & Experiments & \\
\hline$\Phi_{m 0}$ & Initial porosity for coal matrix & 0.045 & & Experiments & \\
\hline$\Phi_{f 0}$ & Initial porosity for fracture & 0.018 & & Experiments & \\
\hline$b_{0}$ & Initial fracture aperture & $1 \times 10^{-5}$ & $\mathrm{~m}$ & References & Wu et al, 2010 \\
\hline$a_{0}$ & Initial matrix size & 0.01 & $\mathrm{~m}$ & References & Wu et al, 2010 \\
\hline$C_{s}$ & Specific heat capacity of coal skeleton & 1350 & $\mathrm{~J} \cdot \mathrm{kg}^{-1} \cdot \mathrm{K}^{-1}$ & References & Zhu et al, 2011 \\
\hline$C_{w}$ & Specific heat capacity of water & 4200 & $\mathrm{~J} \cdot \mathrm{kg}^{-1} \cdot \mathrm{K}^{-1}$ & References & Zhu et al, 2011 \\
\hline$C_{g}$ & Specific heat capacity of gas & 2160 & $\mathrm{~J} \cdot \mathrm{kg}^{-1} \cdot \mathrm{K}^{-1}$ & References & Zhu et al, 2011 \\
\hline$c$ & Temperature coefficient of water & 0.0228 & $\mathrm{~kg} \cdot \mathrm{m}^{-3} \cdot \mathrm{K}^{-1}$ & Experiments & \\
\hline$p_{c g w}$ & Capillary pressure & 0.05 & $\mathrm{MPa}$ & Experiments & \\
\hline$\mu_{g}$ & Gas dynamic viscosity & $1.84 \times 10^{-5}$ & $\mathrm{~Pa} \cdot \mathrm{s}$ & References & Wu et al, 2010 \\
\hline$\mu_{w}$ & Water dynamic viscosity & $1.01 \times 10^{-3}$ & $\mathrm{~Pa} \cdot \mathrm{s}$ & Experiments & \\
\hline$\rho_{s}$ & Density of coal skeleton & 1470 & $\mathrm{~kg} \cdot \mathrm{m}^{-3}$ & Experiments & \\
\hline$\rho_{w a}$ & Density of water at standard condition & 1000 & $\mathrm{~kg} \cdot \mathrm{m}^{-3}$ & Experiments & \\
\hline$T_{t}$ & $\begin{array}{l}\text { Reference temperature for } \\
\text { desorption/adsorption test of gas }\end{array}$ & 300 & $\mathrm{~K}$ & References & Xia et al, 2015 \\
\hline$\lambda_{s}$ & Thermal conductivity of coal skeleton & 0.191 & $\mathrm{~W} \cdot \mathrm{m}^{-1} \cdot \mathrm{K}^{-1}$ & References & Zhu et al, 2011 \\
\hline
\end{tabular}




\begin{tabular}{|c|c|c|c|c|c|}
\hline$\lambda_{g}$ & Thermal conductivity of gas & 0.031 & $\mathrm{~W} \cdot \mathrm{m}^{-1} \cdot \mathrm{K}^{-1}$ & References & Zhu et al, 2011 \\
\hline$\lambda_{w}$ & Thermal conductivity of water & 0.598 & $\mathrm{~W} \cdot \mathrm{m}^{-1} \cdot \mathrm{K}^{-1}$ & Experiments & \\
\hline$\alpha_{T}$ & $\begin{array}{l}\text { Volumetric thermal expansion } \\
\text { coefficient of coal skeleton }\end{array}$ & $2.4 \times 10^{-5}$ & $\mathrm{~K}^{-1}$ & References & Zhu et al, 2011 \\
\hline$P_{L}$ & Langmuir pressure constant & 3.034 & $\mathrm{MPa}$ & Experiments & \\
\hline$V_{L}$ & Langmuir volume constant & 0.036 & $\mathrm{~m}^{3} \cdot \mathrm{kg}^{-1}$ & Experiments & \\
\hline$\alpha_{s g}$ & $\begin{array}{l}\text { Coefficient for sorption-induced } \\
\text { volumetric strain }\end{array}$ & 0.06 & $\mathrm{~kg} \cdot \mathrm{m}^{-3}$ & Experiments & \\
\hline$d_{1}$ & Pressure coefficient of gas & 0.07 & $\mathrm{MPa}^{-1}$ & References & Xia et al, 2015 \\
\hline$d_{2}$ & Temperature coefficient of gas & 0.02 & $\mathrm{~K}^{-1}$ & References & Xia et al, 2015 \\
\hline$q_{s t}$ & Isosteric heat of adsorption & 33.4 & $\mathrm{~kJ} \cdot \mathrm{mol}^{-1}$ & Experiments & \\
\hline$s_{w i}$ & Initial water saturation & 0.8 & & Field data & \\
\hline$k_{r w 0}$ & Endpoint relative permeability of water & 1.0 & & Experiments & \\
\hline$k_{r g 0}$ & Endpoint relative permeability of gas & 0.756 & & Experiments & \\
\hline$s_{w r}$ & Irreducible water saturation & 0.52 & & Experiments & \\
\hline$s_{g r}$ & Residual gas saturation & 0.05 & & Estimation & \\
\hline$b_{1}$ & Klinkenberg factor & 0.76 & $\mathrm{MPa}$ & References & Zhu et al, 2011 \\
\hline
\end{tabular}

\subsection{Model validation}

Fig. 5 shows the gas and water production rates obtained through field data and simulations. Field data recorded production rate of No. 1 CBM well in southern district of Fanzhuang block from June 20, 2009 to October 8, 2011 (840 days). During the monitoring period, the gas/water production was recorded daily, and 840 data sets were obtained. Due to the large amount of field data, the average value of every 10 days' gas/water production rate, namely 84 data sets, was adopted in the Fig. 5. The simulation results of 1000 days' CBM extractions were recorded by every 10 days' average value with the line type of continuous curve in the figure. In order to facilitate analysis, the average value is called as the gas/water production rate in the following study.

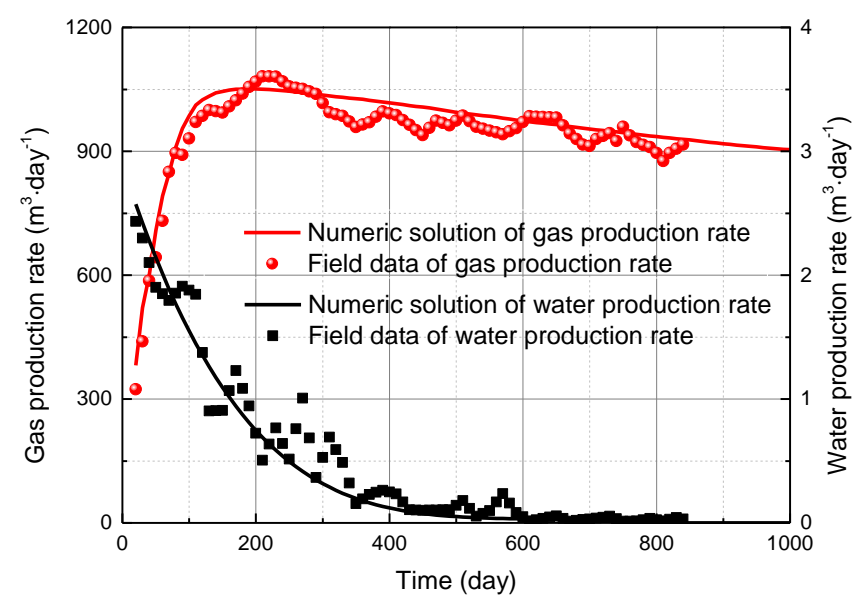

Fig. 5. The comparison between numerical solutions and field data of the gas production rate and water production rate in NO.1 CBM well

The gas production rate of No. 1 CBM well firstly increases and then gradually decreases with time. The average gas production rate of field data during the whole monitoring period is 929.5 $\mathrm{m}^{3} \cdot$ day $^{-1}$ and the maximum value is $1081 \mathrm{~m}^{3} \cdot$ day $^{-1}$ approximately appeared at the 220 days. The average gas production rate of simulation result is $951.2 \mathrm{~m}^{3} \cdot \mathrm{day}^{-1}$ and the maximum value is $1051.2 \mathrm{~m}^{3} \cdot \mathrm{day}^{-1}$ appeared at the 200 days. The water production rate has a trend of gradually 
reduction over time. During water drainage period (about 350 days), the average water production rate of field data is $1.145 \mathrm{~m}^{3} \cdot$ day $^{-1}$, and the value of simulation result is $1.093 \mathrm{~m}^{3} \cdot \mathrm{day}^{-1}$. After extracting 600 days, the average water production rate is almost equal to zero. The gas/water production rate of both field data and simulation result maintains consistent trends and the value fits very well, with the error being $2.33 \%$ for average gas production rate and $4.54 \%$ for average water production rate, which shows high accuracy of proposed model.

\subsection{Model comparisons}

To investigate changing rule of gas pressure, permeability and gas production in the process of CBM extraction under different coupled models, a total of four scenarios were considered (Table

2). (Zhao et al., 2004; Zhu et al., 2011; Thararoop et al., 2012)

Scenarios I (Zhao' model): neglect the affect of water and temperature; merely consider the gas-solid coupling effect.

Scenarios II (Zhu' model): consider the effect of temperature on the basis of scenarios I, neglect the affect of water.

Table 2 Different coupling models for CBM extraction

\begin{tabular}{lcccc}
\hline & Zhao' model & Zhu' model & Thararoop' model & proposed model \\
\hline Relation (1) & $\sqrt{ }$ & $\sqrt{ }$ & $\sqrt{ }$ & $\sqrt{ }$ \\
Relation (2) & $\times$ & $\times$ & $\sqrt{ }$ & $\sqrt{ }$ \\
Relation (3) & $\times$ & $\sqrt{ }$ & $\times$ & $\sqrt{ }$ \\
Relation (4) & $\sqrt{ }$ & $\sqrt{ }$ & $\sqrt{ }$ & $\sqrt{ }$ \\
Relation (5) & $\times$ & $\times$ & $\sqrt{ }$ & $\sqrt{ }$ \\
Relation (6) & $\times$ & $\sqrt{ }$ & $\times$ & $\sqrt{ }$ \\
Relation (7) & $\times$ & $\times$ & $\sqrt{ }$ & $\sqrt{ }$ \\
Relation (8) & $\times$ & $\times$ & $\sqrt{ }$ & $\sqrt{ }$ \\
Relation (9) & $\times$ & $\times$ & $\times$ & $\sqrt{ }$ \\
Relation (10) & $\times$ & $\sqrt{ }$ & $\times$ & $\sqrt{ }$ \\
Relation (11) & $\times$ & $\sqrt{ }$ & $\times$ & $\sqrt{ }$ \\
Relation (12) & $\times$ & $\times$ & $\times$ & \\
\hline
\end{tabular}

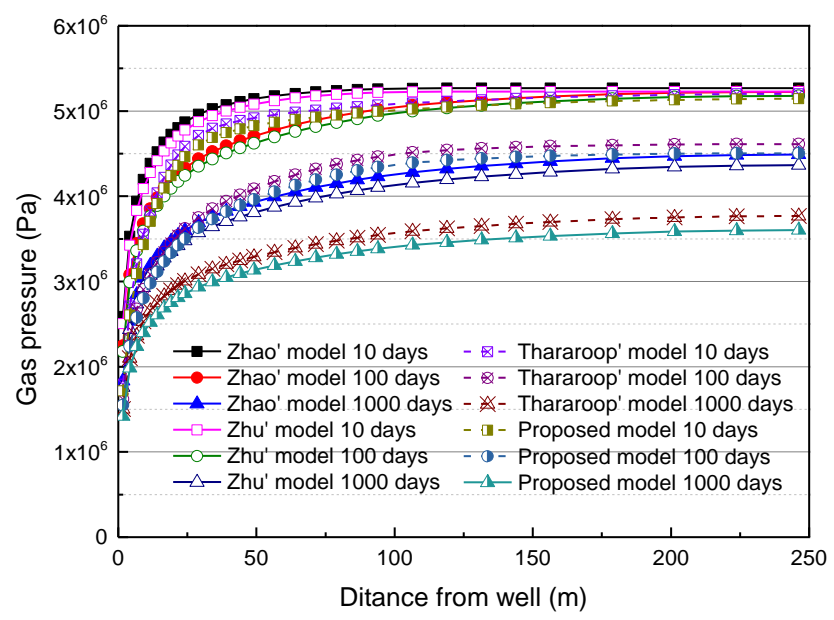

(a) Gas pressure distribution along the reference line O-A ( $\mathrm{t}=10,100$ and 1000 days, respectively) 


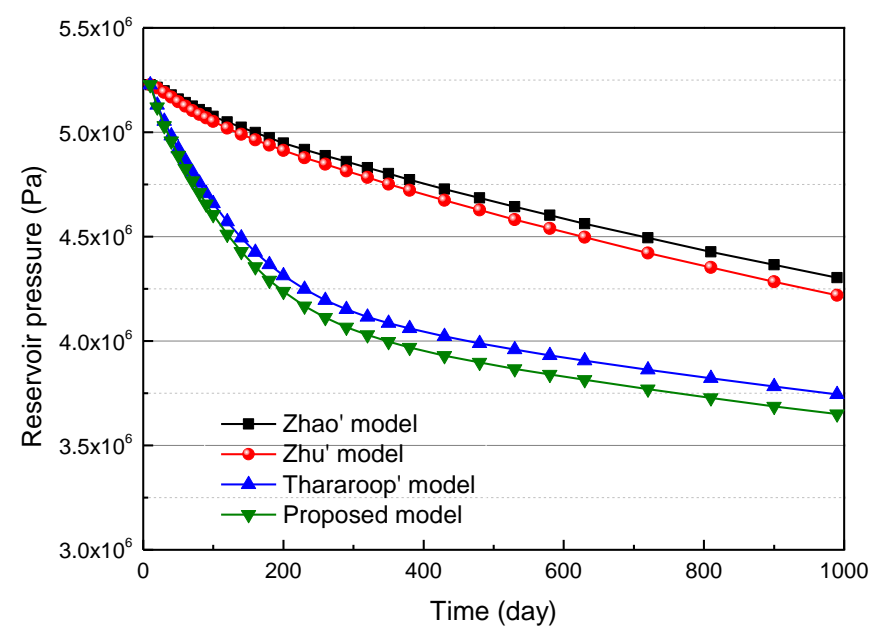

(b) Gas pressure distribution at the reference point $\mathrm{B}(\mathrm{t}=[0,1000]$ days)

Fig. 6. The gas pressure variation of different coupled models

Scenarios III (Thararoop' model): consider the effect of water on the basis of scenarios I, neglect the affect of temperature.

Scenarios IV (proposed model): consider gas-solid interaction with thermal effect, meanwhile, take gas-water two-phase flow into account.

A red line $\mathrm{O}-\mathrm{A}$ and point $\mathrm{B}$ as the observation reference was drawn to analyze the variation law of permeability and gas pressure in the coal reservoir during CBM extraction with different coupled models (Fig. 4).

Gas pressure variation of different coupled models in the reference line O-A is shown in Fig. 6 a, which appears that the gas pressure dropping area has a funnel shape. The closer distance from gas well wall, the greater pressure dropping value is observed. Figure $6 \mathrm{~b}$ exhibits the gas pressure variation at point B (within 1000 days). It is found that gas pressure decreases with time and differs from different coupled models, for example the gas pressures at the same time (e.g. 500 days) are: Zhao' model (4.66 MPa) > Zhu' model (4.60 MPa) > Thararoop' model (3.97 MPa) > proposed model (3.88 MPa), respectively. In terms of the gas pressure dropping value, the model considered the thermal effect or water (two-phase flow) effect is larger than when these two parameters were not considered, especially gas pressure reduced rapidly during the drainage period (the early stage of CBM extraction). Compared with the model we proposed (point B, 500 days), the Thararoop' model ignores the thermal effect, the Zhu' model ignores water effect and the Zhao 'model ignores the both effects, and the gas pressure increases by $2.32 \%, 18.56 \%$ and $20.1 \%$, respectively. With gas pressure dropping, the adsorbed methane in the coal matrix desorbs continuously to inhibit gas pressure decline, and after a period of extraction, the water in the reservoir is almost extracted out which results the dropping speed of gas pressure slows down.

Fig. 7 displays the permeability rate variation of different coupled models. Under the integrative impact of crustal stress, methane, water and temperature, the original permeability in coal reservoir is 0.94822 of the given initial permeability $k_{0}$ under freedom condition. The order of permeability rate of different coupled models is: proposed model $>$ Zhu' model $>$ Zhao' model > Thararoop' model, successively. According to the effective stress principle, when gas pressure decreases, the actually effective stress of coal skeleton will increase, which leads to a reduction of porosity and permeability in coal reservoir. For the coupled model (Thararoop' model and proposed model), the permeability rate changes quickly in the drainage period and the closer 
distance from gas well wall, the greater impacts of CBM extraction on the permeability rate will be.

For the coupled model without considering thermal effect (Zhao' model and Thararoop' model), the porosity and permeability decreases with gas pressure dropping, for example, the permeability rate $k / k_{0}$ closed to the CBM well at 1000 days reduces by $0.704 \%$ and $0.749 \%$ when compared with the original permeability. After taking thermal effect into account (Zhu' model and proposed model), the porosity and permeability gradually increases, the permeability rate $k / k_{0}$ increases by $1.586 \%$ and $1.683 \%$. In terms of the mechanism, the coupling process of coalbed methane migration is established on the dynamic evolution of permeability. The permeability is the competition result of two opposite effects: the matrix shrinkage effect caused by temperature reduction, the matrix swelling effect caused by gas pressure decrease and methane adsorption increase. In case of water and methane depletion, the reservoir permeability of models considered the thermal effect gradually rises, and a larger permeability increasing value is observed for the proposed model due to its greater heat taken away by extracted water.

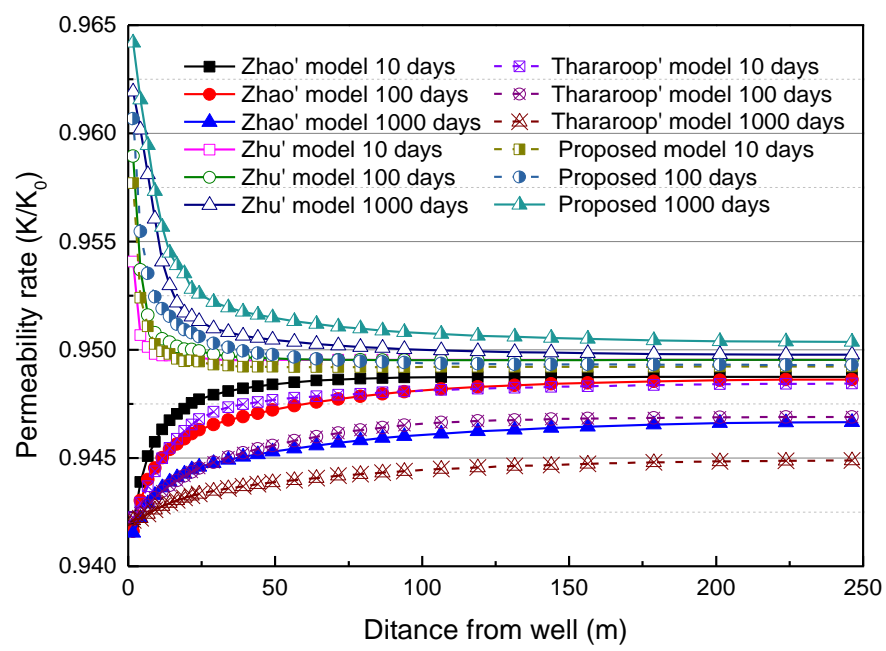

(a) Permeability rate distribution along the reference line $\mathrm{O}-\mathrm{A}(\mathrm{t}=10,100$ and 1000 days, respectively)

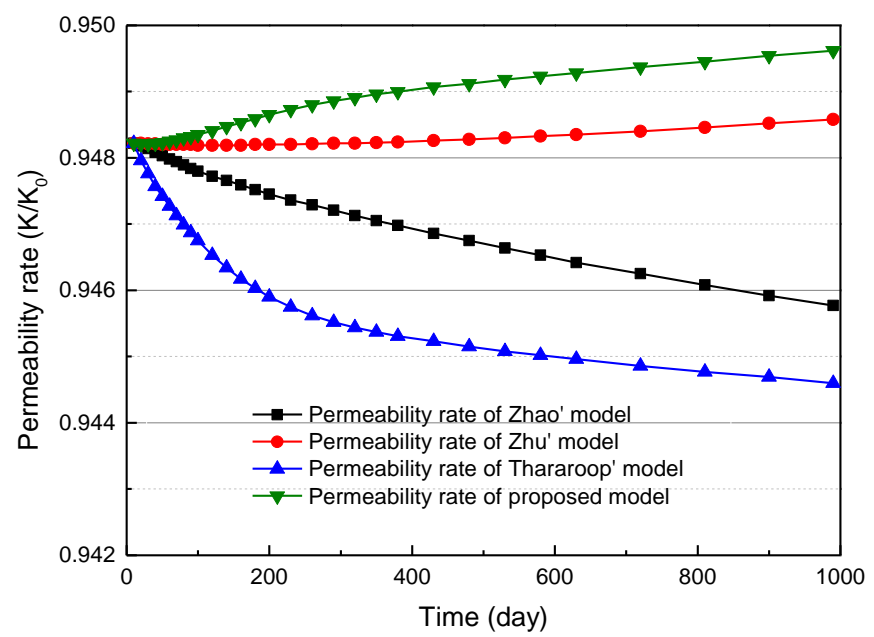

(b) Permeability rate distribution at the reference point $\mathrm{B}$ ( $\mathrm{t}=[0,1000]$ days)

Fig. 7. The permeability rate variation of different coupled models

Fig. 8 shows the gas production rate variation of different coupled models within 1000 days. 
It is observed that the gas production rate of models considered the thermal effect is larger than without it. Overall, the order of gas production rates of different coupled models is: Zhu' model > Zhao' model > proposed model > Thararoop' model, successively. The gas production rate of coupled models ignoring the influence of water (Zhao' model and Zhu' model) gradually reduces, with a maximum of $1962 \mathrm{~m}^{3} \cdot$ day $^{-1}$ and $1957 \mathrm{~m}^{3}$. day ${ }^{-1}$ in early stage of extraction, respectively. While after taking water effect into account (Thararoop' model and proposed model), gas production rate first increases and then gradually decreases, with a peak gas production rate at 180 days, $983 \mathrm{~m}^{3} \cdot$ day $^{-1}$ and $1052 \mathrm{~m}^{3} \cdot$ day $^{-1}$, respectively. During the drainage period, gas production rate is small compared with the large water production rate, because there are large amounts of water in coal seam which hinders the methane passage to seep into CBM wells (reflected in the relative permeability). After the drainage period, gas rate increases gradually and reaches the peaking point, then gradually reduces. The model ignored gas-water two-phase flow will overestimate gas production, and the model ignored thermal effect will underestimate gas production, particularly coal seam contains much water.

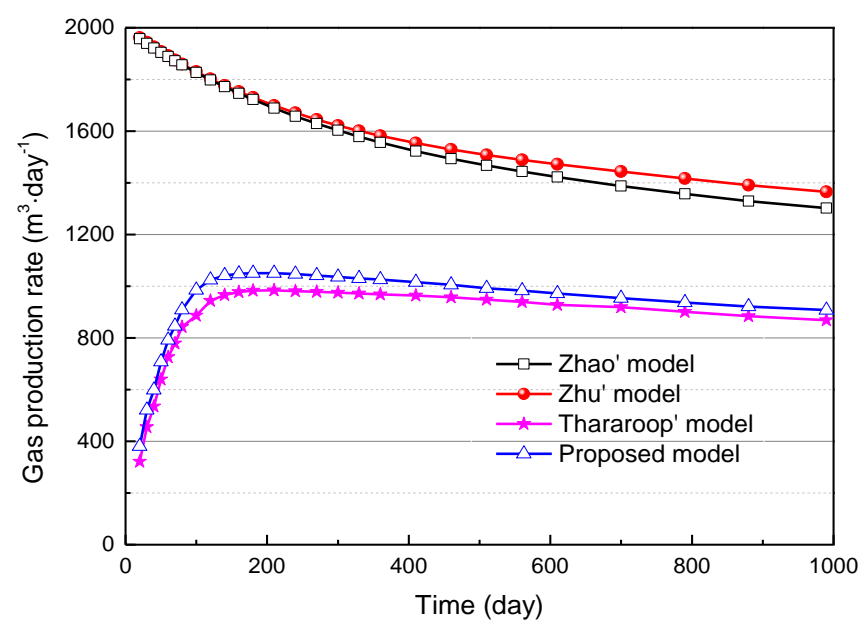

Fig. 8. The gas production rate variation of different coupled models

\section{CBM extraction analyses}

CBM extraction is closely related to the physical factors, including coal permeability/porosity, different initial reservoir temperature, initial water saturation, Langmuir volume constant and Klinkenberg factor. There is no doubt that the influence of porosity and permeability on CBM extraction is huge, which has been widely researched and confirmed in many studies (e.g. Harpalani and Chen, 1997; Palmer and Mansoori, 1998; Cui and Bustin 2005; Pan and Connell, 2007; Zhang et al., 2008; Durucan et al., 2009; Wu et al., 2010b; Liu et al., 2011; Wang et al. 2013). Therefore, the coal permeability/porosity will be no longer discussed here. In the subsequent sections, a number of simulations are conducted to gain insight into the influences of these variables on CBM extraction.

\subsection{Effect of initial reservoir temperature}

Fig. 9 presents the evolutions of gas production rate, permeability rate with different initial reservoir temperature $T_{0}$. It is found in Fig. 9a that gas production rate increases firstly and then gradually decreases, with a peak point at 180 days. The largest gas production rate of the CBM well is observed when $T_{0}=280 \mathrm{~K}$, with a peak gas production rate of $1143 \mathrm{~m}^{3} \cdot$ day $^{-1}$, the following 
are $T_{0}=300 \mathrm{~K}\left(1085 \mathrm{~m}^{3} \cdot\right.$ day $\left.^{-1}\right), 320 \mathrm{~K}\left(1033 \mathrm{~m}^{3} \cdot\right.$ day $\left.^{-1}\right), 340 \mathrm{~K}\left(986 \mathrm{~m}^{3} \cdot\right.$ day $\left.^{-1}\right)$, respectively. The gas production rate decreases with the initial reservoir temperature which is one of the reasons that deep coalbed reservoir has lower gas production due to its higher temperature. According to the Eq. (3), a higher reservoir temperature will lead to smaller absorbed gas content in the unit volume of coal matrix, which results that coalbed methane desorbed from coalbed reservoir is less when the gas pressure drops the same value. As shown in Fig. 9b, the high initial reservoir temperature has a lower permeability than low reservoir temperature at the same time. The matrix shrinkage effect caused by temperature reduction and the matrix swelling effect caused by gas pressure decrease and methane adsorption increase alternately becomes the dominant role of permeability evolution at different positions from CBM well and different extraction time. The permeability rate first declines and then inclines with extraction time, and the turning point occurs at approximately 40 days in this study. This phenomena is also observed in the following variables analyses.

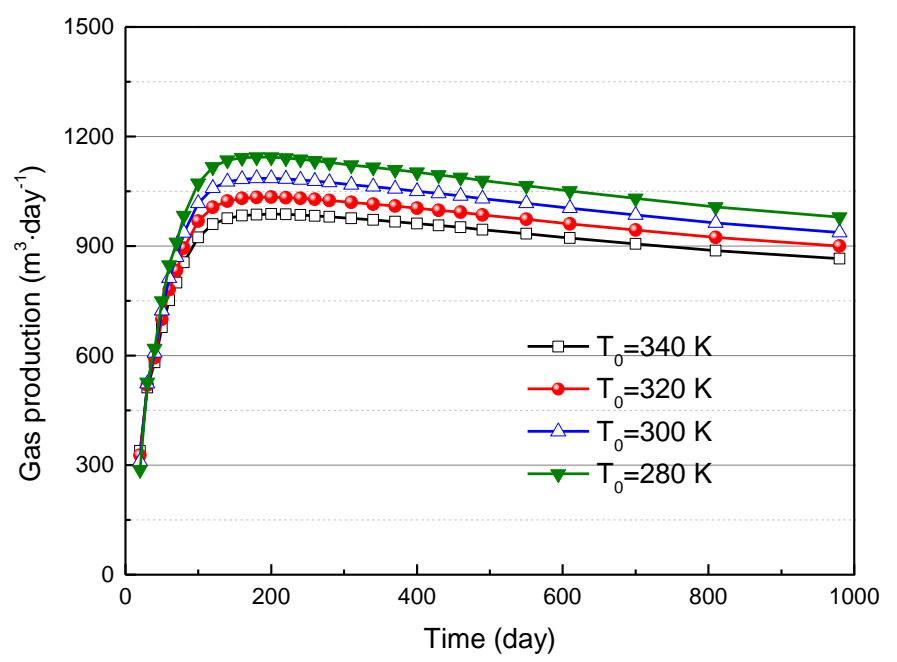

(a) Gas production rate variation of different initial reservoir temperature

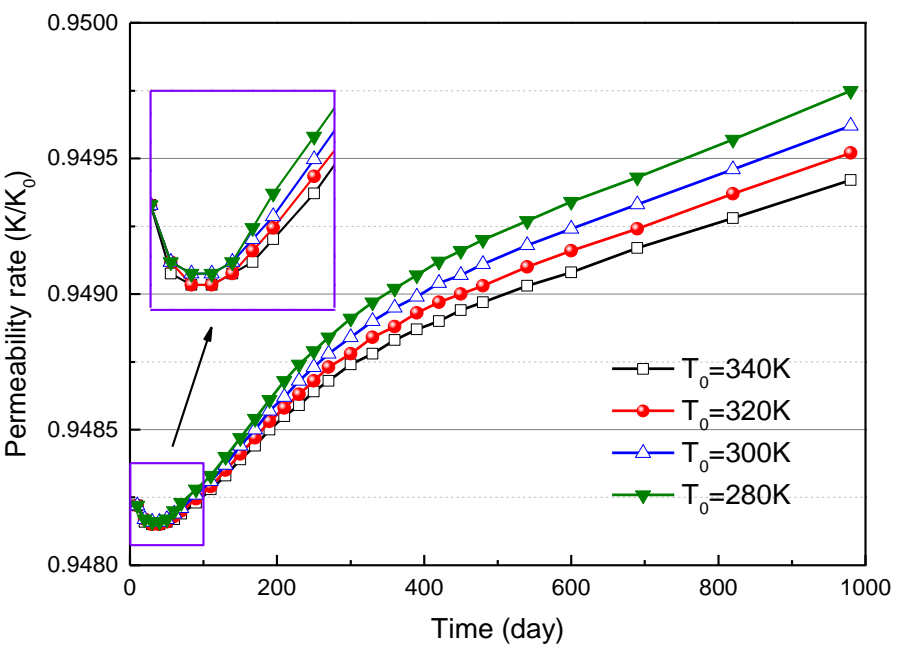

(b) Permeability rate distribution at the reference point $\mathrm{B}$ ( $\mathrm{t}=[0,1000]$ days)

Fig. 9. Evolutions of gas production rate, permeability rate with different initial reservoir temperature

\subsection{Effect of initial water saturation}

Fig. 10 illustrates the evolutions of gas production rate, permeability rate with time when the 
initial water saturation $s_{w i}=0.5,0.6,0.7,0.8$. It is found in Fig. 10a that the initial water saturation $s_{w i}=0.5$ has the largest gas production rate, followed by the initial water saturation $s_{w i}=0.6,0.7$ and 0.8 , respectively, at the same time. When the initial water saturation $s_{w i}=0.8$, the fracture in coal seam is almost occupied by water which results a small gas production rate at the early stage of CBM extraction, merely about $381 \mathrm{~m}^{3} \cdot \mathrm{day}^{-1}$. While gas production rate of $s_{w i}=0.5,0.6,0.7$ at the early stage are 1105,918 and $623 \mathrm{~m}^{3} \cdot$ day $^{-1}$, respectively. It is believed that the initial water saturation not only has an important role on gas production in drainage period but also in whole extraction process. Therefore it should not be ignored. The permeability rate increases with the increasing of initial water saturation (Fig. 10b). Making the initial water saturation $s_{w i}=0.5$ as a reference, the permeability rate of $s_{w i}=0.6,0.7,0.8$ after extraction for 1000 days is increased by $0.062 \%, 0.036 \%$ and $0.021 \%$, respectively.

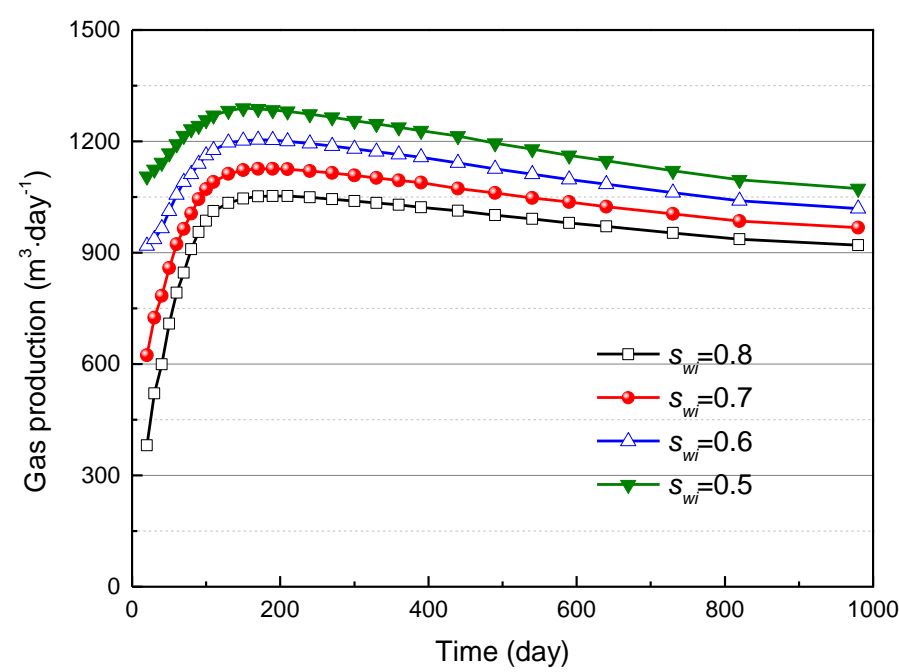

(a) Gas production rate variation of different initial water saturation

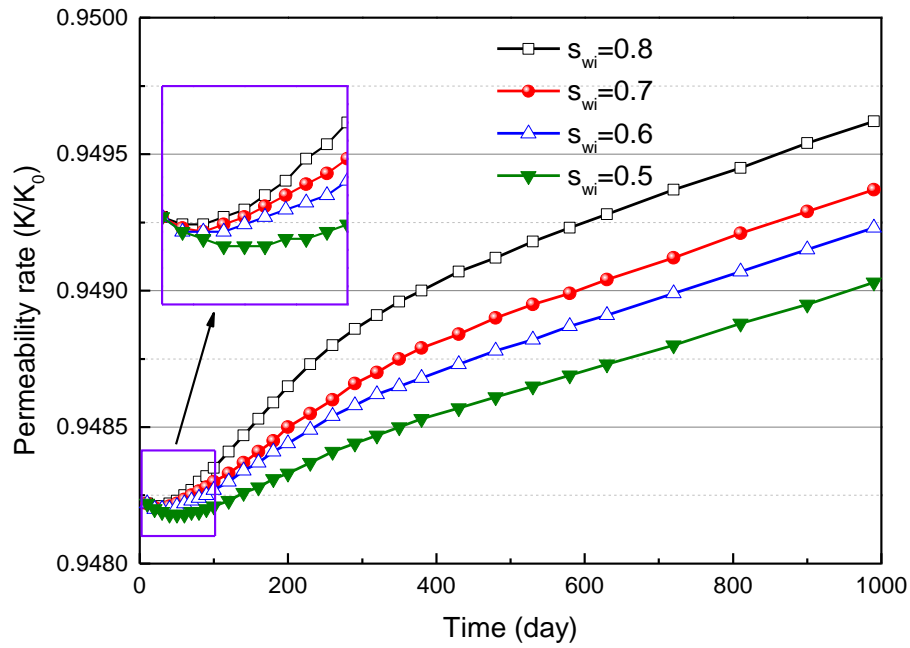

(b) Permeability rate distribution at the reference point $\mathrm{B}(\mathrm{t}=[0,1000]$ days)

Fig. 10. Evolutions of gas production rate, permeability rate with different initial water saturation

\subsection{Effect of Langmuir volume constant}

Fig. 11 shows the evolutions of gas production rate, permeability rate with time when the Langmuir volume constant $V_{L}=0.006,0.016,0.026,0.036 \mathrm{~m}^{3} \cdot \mathrm{kg}^{-1}$. It is observed in Fig. 11a that 
larger Langmuir volume constant corresponds to lower gas production rate and permeability rate. The peak value of gas production rate increase and delay with Langmuir volume constant increasing. When $V_{L}=0.006 \mathrm{~m}^{3} \cdot \mathrm{kg}^{-1}$, the gas production rate is $607 \mathrm{~m}^{3} \cdot$ day $^{-1}$, and when $V_{L}=0.016$, 0.026 and $0.036 \mathrm{~m}^{3} \cdot \mathrm{kg}^{-1}$, the gas production rate is 908,1061 and $1158 \mathrm{~m}^{3} \cdot$ day $^{-1}$, respectively. As shown in Fig. 11b, the permeability rate decreases with the Langmuir volume constant when $V_{L}$ $=0.006 \mathrm{~m}^{3} \cdot \mathrm{kg}^{-1}$, and increases with the Langmuir volume constant when $V_{L}>=0.016 \mathrm{~m}^{3} \cdot \mathrm{kg}^{-1}$, in this study.

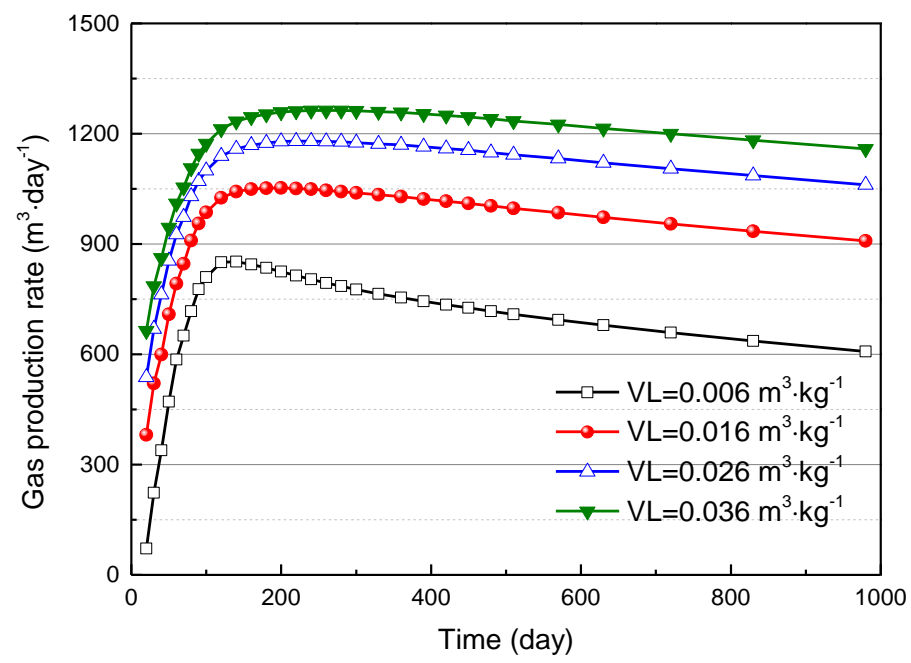

(a) Gas production rate variation of different Langmuir volume constant

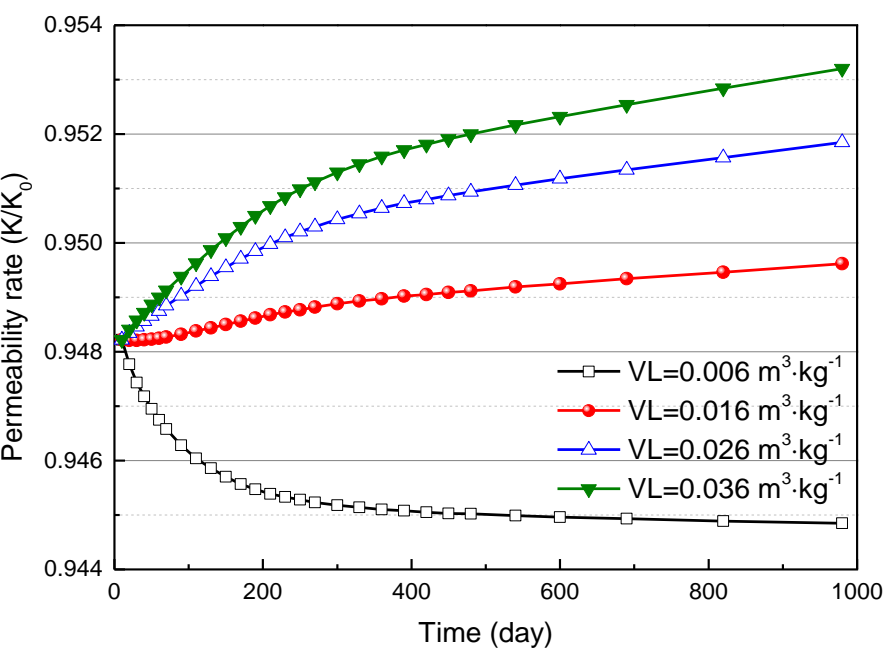

(b) Permeability rate distribution at the reference point $\mathrm{B}(\mathrm{t}=[0,1000]$ days $)$

Fig. 11. Evolutions of gas production rate, permeability rate with different Langmuir volume constant

\subsection{Effect of Klinkenberg factor}

Fig. 12 illustrates the evolutions of gas production rate, permeability rate with time when the Klinkenberg factor $b=0,0.076,0.76,1.52 \mathrm{MPa}$. It is observed that larger Klinkenberg factor corresponds to higher gas production rate and larger permeability rate. The Klinkenberg effect promotes coalbed methane migration significantly, which results in underestimation of gas production, and the impact gradually increases with the drop of gas pressure. 


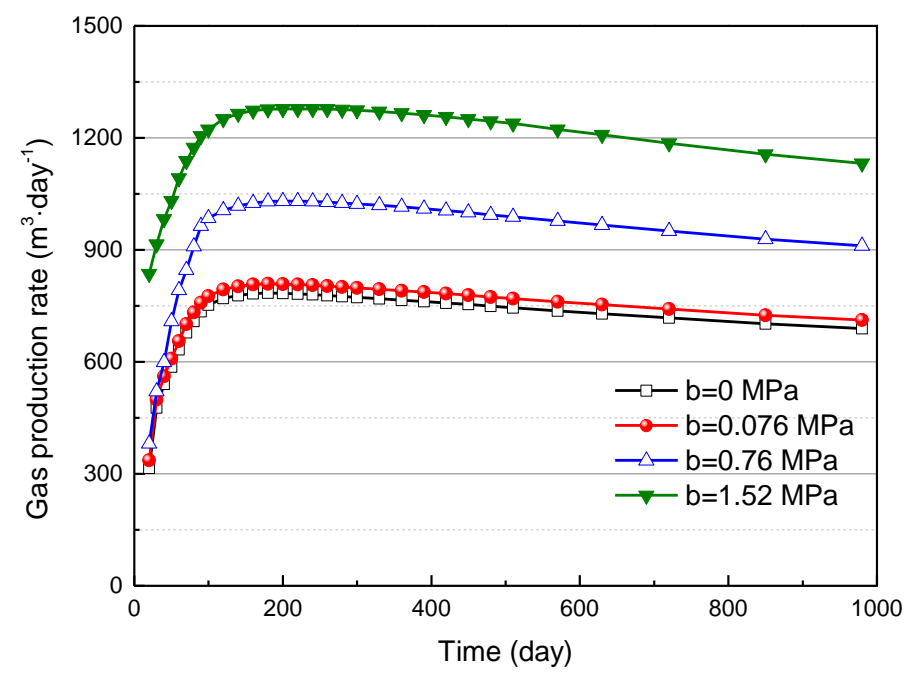

(a) Gas production rate variation of different Klinkenberg factor

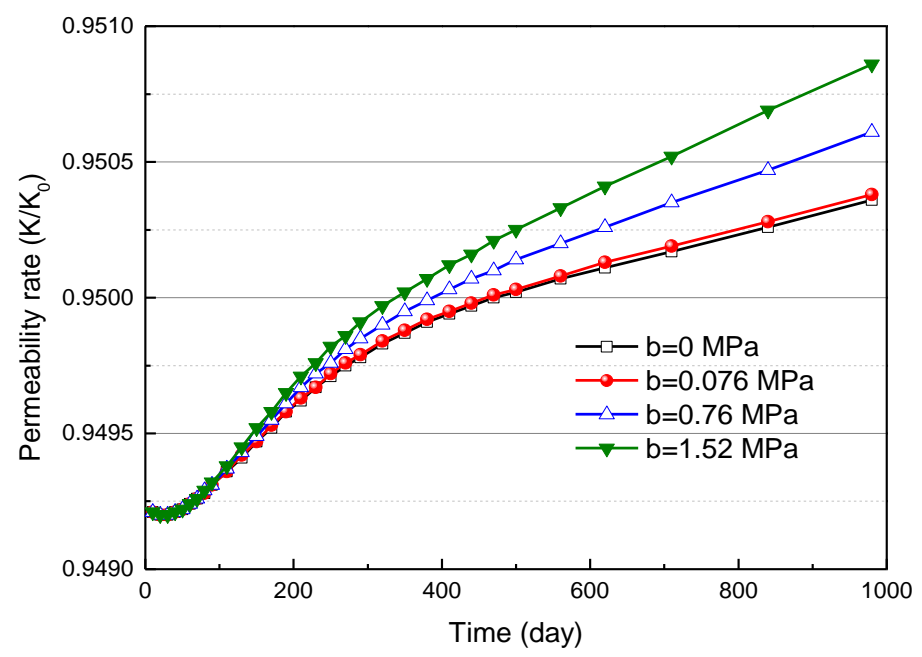

(b) Permeability rate distribution at the reference point $\mathrm{B}(\mathrm{t}=[0,1000]$ days)

Fig. 12. Evolutions of gas production rate, permeability rate with different Klinkenberg factor

\section{Conclusions}

In this work, a fully coupled thermal-hydraulic-mechanical model with two-phase flow for coalbed methane extraction was proposed including coal deformation, gas seepage, water seepage, and thermal transport governing equations. Different coupled models and the influence of several key factors on CBM extraction process were analyzed. The following conclusions can be drawn:

1) The gas production rate and water production rate fits very well when compared the simulation results with field data, which validates the accuracy of proposed THM coupled model.

2) Models considered the thermal effect has a larger gas production rate than without it. The gas production rate of coupled models with no water effect consideration monotonously reduces over time, while when water effect is included, gas production rate first increases and then gradually decreases with a peak point. The model ignored water will overestimate gas production, and the model ignored thermal effect will underestimate gas production, particularly coal seam contains substantial amount of water.

3) The evolution of permeability is the competition result of two opposite effects: the matrix shrinkage effect caused by temperature reduction, the matrix swelling effect caused by gas 
pressure decrease and methane adsorption increase. The reservoir permeability of models considered the thermal effect gradually rises, and a larger permeability increasing value is observed for the proposed model due to its greater heat released by extracted water.

4) The gas production rate decreases with initial reservoir temperature, initial water saturation and Langmuir volume constant, while increases with the Klinkenberg factor. The permeability rate increases with initial water saturation and Klinkenberg factor, and decreases with initial reservoir temperature. In this study, the permeability rate decreases with the Langmuir volume constant when $V_{L}=0.006 \mathrm{~m}^{3} \cdot \mathrm{kg}^{-1}$, and increases with the Langmuir volume constant when $V_{L}>=0.016$ $\mathrm{m}^{3} \cdot \mathrm{kg}^{-1}$. The impact of initial water saturation on gas production can not be ignored in the whole extraction process, especially in the water drainage period. The Klinkenberg effect plays an important role on promoting coalbed methane migration, ignoring it will underestimate the gas production.

\section{Acknowledgements}

This work was funded by the National Science Foundation of China (Grant No. 51004063), the Open Projects of State Key Laboratory for GeoMechanics and Deep Underground Engineering (Grant No. SKLGDUEK1510), the Open Projects of State Key Laboratory of Coal Resources and Safe Mining (Grant No. SKLCRSM15KF04), Natural Science Foundation of Liaoning Province (Grant No. 2015020614) and Liaoning BaiQianWan Talents Program (Grant No. 201575). These supports are gratefully acknowledged. The authors are grateful to the reviewers for discerning comments on this paper.

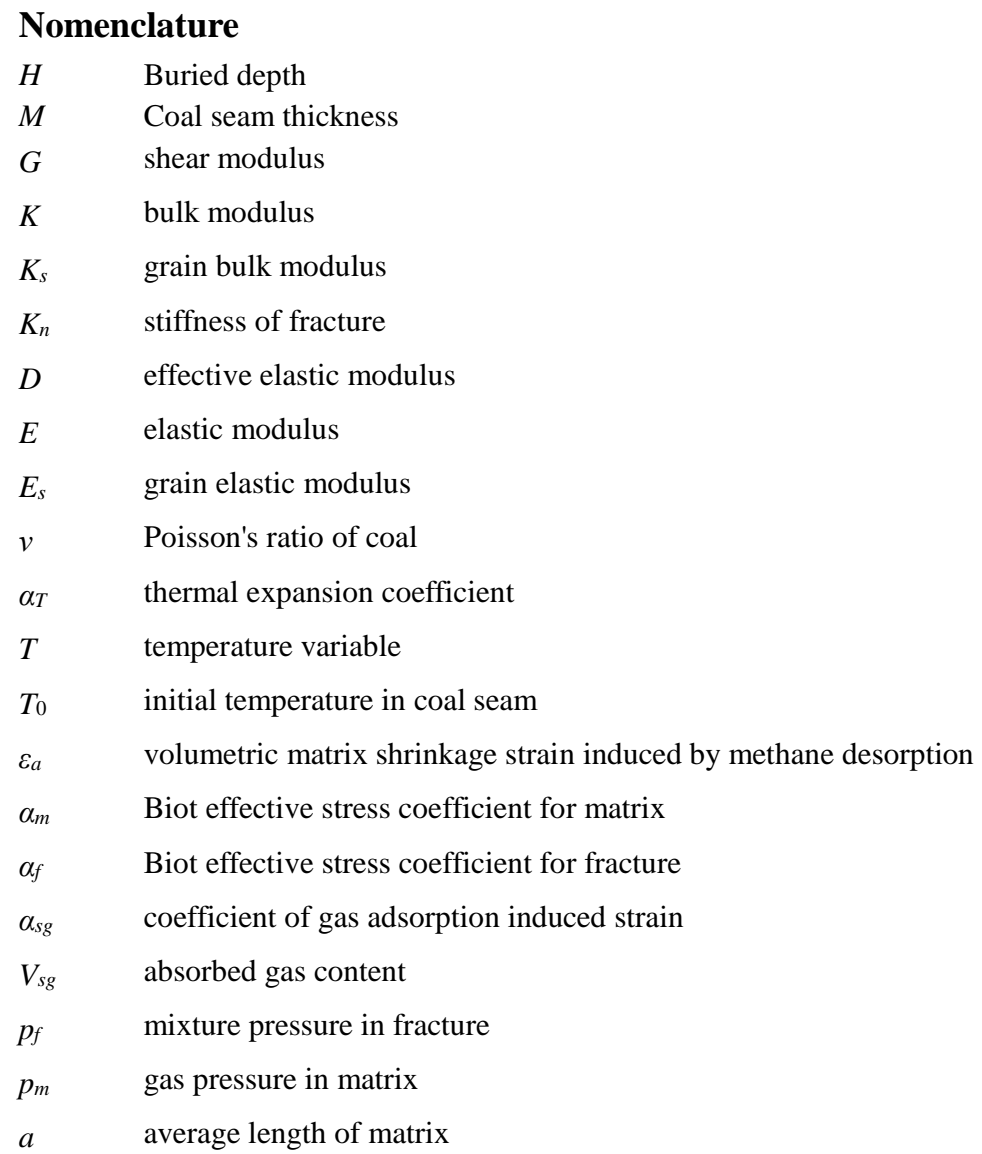




\begin{tabular}{|c|c|}
\hline$b$ & average aperture of fracture \\
\hline$\delta_{i j}$ & Kronecker delta with 1 for $i=j$ and 0 for $i \neq j$ \\
\hline$p_{f w}$ & water pressure in fracture \\
\hline$p_{f g}$ & gas pressure in fracture \\
\hline$s_{w}$ & water saturation \\
\hline$s_{g}$ & gas saturation \\
\hline$d_{1}$ & pressure coefficient for adsorption \\
\hline$d_{2}$ & temperature coefficient for adsorption \\
\hline$V_{L}$ & Langmuir volume constant \\
\hline$p_{L}$ & Langmuir pressure constant \\
\hline$T$ & temperature of coalbed \\
\hline$T_{t}$ & reference temperature for adsorption test \\
\hline$u_{i}$ & displacement in the $i$-direction \\
\hline$f_{i}$ & body force in the $i$-direction \\
\hline$m_{m}$ & methane content in matrix per unit volume \\
\hline$M_{g}$ & methane molar mass \\
\hline$R$ & gas molar constant \\
\hline$t$ & time \\
\hline$\tau$ & methane desorption time \\
\hline$V_{s g}$ & absorbed methane content \\
\hline$\rho_{s}$ & density of coal skeleton \\
\hline$p_{s}$ & standard atmospheric pressure \\
\hline$T_{s}$ & standard temperature \\
\hline$\Phi_{m}$ & porosity in matrix \\
\hline$\Phi_{f}$ & fracture porosity \\
\hline$u_{w}$ & velocity of water \\
\hline$u_{g}$ & velocity of gas \\
\hline$c$ & temperature coefficient of water \\
\hline$\rho_{w s}$ & water density under standard conditions \\
\hline$u_{w}$ & water velocity \\
\hline$u_{g}$ & gas velocity \\
\hline$k$ & absolute permeability of coal \\
\hline$k_{r g 0}$ & endpoint relative permeability of gas \\
\hline$k_{r w 0}$ & endpoint relative permeability of water \\
\hline$k_{r w}$ & relative permeability of water \\
\hline$k_{r g}$ & relative permeability of gas \\
\hline$\mu_{w}$ & dynamic viscosity of water \\
\hline$\mu_{g}$ & dynamic viscosity of gas \\
\hline$b_{1}$ & Klinkenberg factor \\
\hline$s_{w r}$ & irreducible water saturation \\
\hline$s_{g r}$ & residual gas saturation \\
\hline$p_{c g w}$ & capillary pressure \\
\hline$C_{g}$ & specific heat capacity of gas \\
\hline$C_{w}$ & specific heat capacity of water \\
\hline
\end{tabular}




$\begin{array}{ll}\left(\rho C_{p}\right)_{e f f} & \text { effective heat capacity } \\ \lambda_{e f f} & \text { effective coefficient of isotropic thermal conductivity } \\ C_{s} & \text { specific heat capacity of coal skeleton } \\ \lambda_{s} & \text { heat conductivity coefficient of coal skeleton } \\ \lambda_{g} & \text { heat conductivity coefficient of gas } \\ \lambda_{w} & \text { heat conductivity coefficient of water } \\ q_{s t} & \text { isosteric heat of adsorption } \\ \varepsilon_{v} & \text { volumetric strain of coal } \\ K_{f} & \text { modified fracture stiffness }\end{array}$

\section{Subscript}

0 initial value of the variable

m matrix

f fracture

\section{References}

Aguado, M. B. D., Nicieza, C. G., 2007. Control and prevention of gas outbursts in coal mines, Riosa-Olloniego coalfield, Spain. Int. J. Coal Geol. 69(4), 253-266.

An, F. H., Cheng, Y. P., Wang, L., Li, W., 2013. A numerical model for outburst including the effect of adsorbed gas on coal deformation and mechanical properties. Comput. Geotech. 54, 222-231.

Biot, M. A., 1941. General theory of three-dimensional consolidation. J. Appl. Phys. 12(2), 155-164.

Cai, Y., Liu, D., Yao, Y., Li, J., Qiu, Y., 2011. Geological controls on prediction of coalbed methane of No. 3 coal seam in Southern Qinshui Basin, North China. Int. J. Coal Geol. 88(2), 101-112.

Chen, D., Shi, J. Q., Durucan, S., Korre, A., 2014. Gas and water relative permeability in different coals: model match and new insights. Int. J. Coal Geol. 122, 37-49.

Cheng, Y. P., Wang, L., Zhang, X. L., 2011. Environmental impact of coal mine methane emissions and responding strategies in China. Int. J. Greenh. Gas Control 5(1), 157-166.

Clarkson, C. R., Bustin, R. M., Levy, J. H., 1997. Application of the mono/multilayer and adsorption potential theories to coal methane adsorption isotherms at elevated temperature and pressure. Carbon, 35(12), 1689-1705.

Clarkson, C. R., Rahmanian, M., Kantzas, A., Morad, K., 2011. Relative permeability of CBM reservoirs: controls on curve shape. Int. J. Coal Geol. 88(4), 204-217.

Clarkson, C. R., Qanbari, F., 2015. Transient flow analysis and partial water relative permeability curve derivation for low permeability undersaturated coalbed methane wells. Int. J. Coal Geol. 152, 110-124.

COMSOL, A.B., 2012. COMSOL Multiphysics Version 4.3: User's Guide and Reference Guide. www.comsol.com.

Connell L D., 2009. Coupled flow and geomechanical processes during gas production from coal seams. Int. J. Coal Geol. 79(1): 18-28.

Corey, A. T., 1954. The interrelation between gas and oil relative permeability. Prod. Mon. 31, 533-546

Crosdale, P. J., Moore, T. A., Mares, T. E., 2008. Influence of moisture content and temperature on methane adsorption isotherm analysis for coals from a low-rank, biogenically-sourced gas reservoir. Int. J. Coal Geol. 76(1), 166-174.

Cui, X., Bustin, R. M., 2005. Volumetric strain associated with methane desorption and its impact on coalbed gas production from deep coal seams. AAPG Bull. 89(9), 1181-1202. 
Durucan, S., Ahsanb, M., Shia, J. Q., 2009. Matrix shrinkage and swelling characteristics of European coals. Energy Procedia 1(1), 3055-3062.

Gentzis, T., Goodarzi, F., Cheung, F. K., Laggoun-Défarge, F., 2008. Coalbed methane producibility from the Mannville coals in Alberta, Canada: A comparison of two areas. Int. J. Coal Geol. 74(3), 237-249.

Gu, F., Chalaturnyk, R., 2010. Permeability and porosity models considering anisotropy and discontinuity of coalbeds and application in coupled simulation. J. Petrol. Sci. Eng. 74(3), 113-131.

Guo, H., Yu, Z., Zhang, H., 2015. Phylogenetic diversity of microbial communities associated with coalbed methane gas from Eastern Ordos Basin, China. Int. J. Coal Geol. 150, 120-126.

Gunter, W. D., Gentzis, T., Rottenfusser, B. A., Richardson, R. J. H., 1997. Deep coalbed methane in Alberta, Canada: a fuel resource with the potential of zero greenhouse gas emissions. Energy Convers. Manage. 38, S217-S222.

Han, F., Busch, A., van Wageningen, N., Yang, J., Liu, Z., Krooss, B. M., 2010. Experimental study of gas and water transport processes in the inter-cleat (matrix) system of coal: anthracite from Qinshui Basin, China. Int. J. Coal Geol. 81(2), 128-138.

Han, J., Zhang, H. W., Li, S., Song, W. H., 2012. The characteristic of in situ stress in outburst area of China. Saf. Sci. 50(4), 878-884.

Harpalani, S., Schraufnagel, R. A., 1990. Shrinkage of coal matrix with release of gas and its impact on permeability of coal. Fuel 69(5), 551-556.

Harpalani, S., Chen, G., 1997. Influence of gas production induced volumetric strain on permeability of coal. Geotech. Geol. Eng. 15(4), 303-325.

Hu, G., Wang, H., Fan, X., Yuan, Z., Hong, S., 2009. Mathematical model of coalbed gas flow with Klinkenberg effects in multi-physical fields and its analytic solution. Transp. Porous Media 76(3), 407-420.

Karacan, C. Ö., Ruiz, F. A., Cotè, M., Phipps, S., 2011. Coal mine methane: a review of capture and utilization practices with benefits to mining safety and to greenhouse gas reduction. Int. J. Coal Geol. 86(2), 121-156. Klinkenberg L J., 1941. The permeability of porous media to liquids and gases. In: Drilling and production practice. American Petroleum Institute, 200-213.

Kumar, H., Elsworth, D., Liu, J., Pone, D., Mathews, J. P., 2015. Permeability evolution of propped artificial fractures in coal on injection of CO2. J. Petrol. Sci. Eng. 133, 695-704.

Liu, J., Chen, Z., Elsworth, D., Qu, H., Chen, D., 2011. Interactions of multiple processes during CBM extraction: a critical review. Int. J. Coal Geol. 87(3), 175-189.

Liu, Q., Cheng, Y., Zhou, H., Guo, P., An, F., Chen, H., 2014. A mathematical model of coupled gas flow and coal deformation with gas diffusion and klinkenberg effects. Rock Mech. Rock Eng. 48(3), 1163-1180.

Morad, K., 2012. Selected topics in coalbed methane reservoirs. J. Nat. Gas Sci. Eng. 8, 99-105.

Pashin, J., 1998. Stratigraphy and structure of coalbed methane reservoirs in the United States: an overview. Int. J. Coal Geol. 35(1), 209-240.

Palmer, I., Mansoori, J., 1998. How permeability depends on stress and pore pressure in coal beds: A new model. SPE Reserv. Eval. Eng. 1(6), 539-544.

Palmer, I., 2010. Coalbed methane completions: a world view. Int. J. Coal Geol. 82(3), 184-195.

Pan, Z., Connell, L.D., 2007. A theoretical model for gas adsorption induced coal swelling. Int. J. Coal Geol. 69(4), 243-252.

Rutqvist, J., Wu, Y. S., Tsang, C. F., Bodvarsson, G., 2002. A modeling approach for analysis of coupled multiphase fluid flow, heat transfer, and deformation in fractured porous rock. Int. J. Rock Mech. Min. Sci. 39(4), 429-442.

Salmachi, A., Yarmohammadtooski, Z., 2015. Production data analysis of coalbed methane wells to estimate the 
time required to reach to peak of gas production. Int. J. Coal Geol. 141, 33-41.

Sayyafzadeh, M., Keshavarz, A., Alias, A. R. M., Dong, K. A., Manser, M., 2015. Investigation of varying-composition gas injection for coalbed methane recovery enhancement: A simulation-based study. J. Nat. Gas Sci. Eng. 27, 1205-1212.

Sobczyk, J., 2011. The influence of sorption processes on gas stresses leading to the coal and gas outburst in the laboratory conditions. Fuel 90(3), 1018-1023.

Sobczyk, J., 2014. A comparison of the influence of adsorbed gases on gas stresses leading to coal and gas outburst. Fuel 115, 288-294.

Tao, S., Tang, D., Xu, H., Gao, L., Fang, Y., 2014. Factors controlling high-yield coalbed methane vertical wells in the Fanzhuang Block, Southern Qinshui Basin. Int. J. Coal Geol. 134, 38-45.

Thararoop, P., Karpyn, Z. T., Ertekin, T., 2012. Development of a multi-mechanistic, dual-porosity, dual-permeability, numerical flow model for coalbed methane reservoirs. J. Nat. Gas Sci. Eng. 8, 121-131.

Wang, H., Cheng, Y., Wang, W., Xu, R., 2014. Research on comprehensive CBM extraction technology and its applications in China's coal mines. J. Nat. Gas Sci. Eng. 20, 200-207.

Wang, G., Ren, T., Wang, K., Zhou, A., 2014. Improved apparent permeability models of gas flow in coal with Klinkenberg effect. Fuel 128, 53-61.

Wang, J. G., Liu, J., Kabir, A., 2013. Combined effects of directional compaction, non-Darcy flow and anisotropic swelling on coal seam gas extraction. Int. J. Coal Geol. 109, 1-14.

Wold, M. B., Connell, L. D., Choi, S. K., 2008. The role of spatial variability in coal seam parameters on gas outburst behaviour during coal mining. Int. J. Coal Geol. 75(1), 1-14.

Wu, Y., Liu, J., Elsworth, D., Chen, Z., Connell, L., Pan, Z., 2010. Dual poroelastic response of a coal seam to CO 2 injection. Int. J. Greenh. Gas Control 4(4), 668-678.

Wu, Y., Liu, J., Elsworth, D., Miao, X., Mao, X., 2010b. Development of anisotropic permeability during coalbed methane production. J. Nat. Gas Sci. Eng. 2(4), 197-210.

Wu, Y., Liu, J., Chen, Z., Elsworth, D., Pone, D., 2011. A dual poroelastic model for CO 2-enhanced coalbed methane recovery. Int. J. Coal Geol. 86(2), 177-189.

Xia, T., Zhou, F., Liu, J., Hu, S., Liu, Y., 2014. A fully coupled coal deformation and compositional flow model for the control of the pre-mining coal seam gas extraction. Int. J. Rock Mech. Min. Sci. 72, 138-148.

Xia, T., Zhou, F., Gao, F., Kang, J., Liu, J., Wang, J., 2015. Simulation of coal self-heating processes in underground methane-rich coal seams. Int. J. Coal Geol. 141, 1-12.

Xu, H., Tang, D. Z., Tang, S. H., Zhao, J. L., Meng, Y. J., Tao, S., 2014. A dynamic prediction model for gas-water effective permeability based on coalbed methane production data. Int. J. Coal Geol. 121, 44-52.

Zhao, Y., Hu, Y., Zhao, B., Yang, D., 2004. Nonlinear coupled mathematical model for solid deformation and gas seepage in fractured media. Transp. Porous Media 55(2), 119-136.

Zhang F. J., Wu Y.; Mao X. B.; Zhang L. P.; Yao B. H., 2012. Coupled thermal-hydrological-mechanical analysis of exploiting coal methane by heat injection. Journal of Mining \& Safety Engineering 04: 505-510. (in Chinese)

Zhang, H., Liu, J., Elsworth, D., 2008. How sorption-induced matrix deformation affects gas flow in coal seams: a new FE model. Int. J. Rock Mech. Min. Sci. 45(8), 1226-1236.

Zhang, R., Yin, X., Winterfeld, P. H., Wu, Y. S., 2016. A fully coupled thermal-hydrological-mechanical-chemical model for CO2 geological sequestration. J. Nat. Gas Sci. Eng. 28, 280-304.

Zhou, L., Feng, Q., Chen, Z., Liu, J., 2012. Modeling and upscaling of binary gas coal interactions in CO2 enhanced coalbed methane recovery. Procedia Environ. Sci. 12, 926-939.

Zhou, H., Yang, Q., Cheng, Y., Ge, C., Chen, J., 2014. Methane drainage and utilization in coal mines with strong coal and gas outburst dangers: A case study in Luling mine, China. J. Nat. Gas Sci. Eng. 20, 357-365. 
Zhu, W. C., Liu, J., Sheng, J. C., Elsworth, D., 2007. Analysis of coupled gas flow and deformation process with desorption and Klinkenberg effects in coal seams. Int. J. Rock Mech. Min. Sci. 44(7), 971-980.

Zhu, W. C., Wei, C. H., Liu, J., Qu, H. Y., Elsworth, D., 2011. A model of coal-gas interaction under variable temperatures. Int. J. Coal Geol. 86(2), 213-221. 


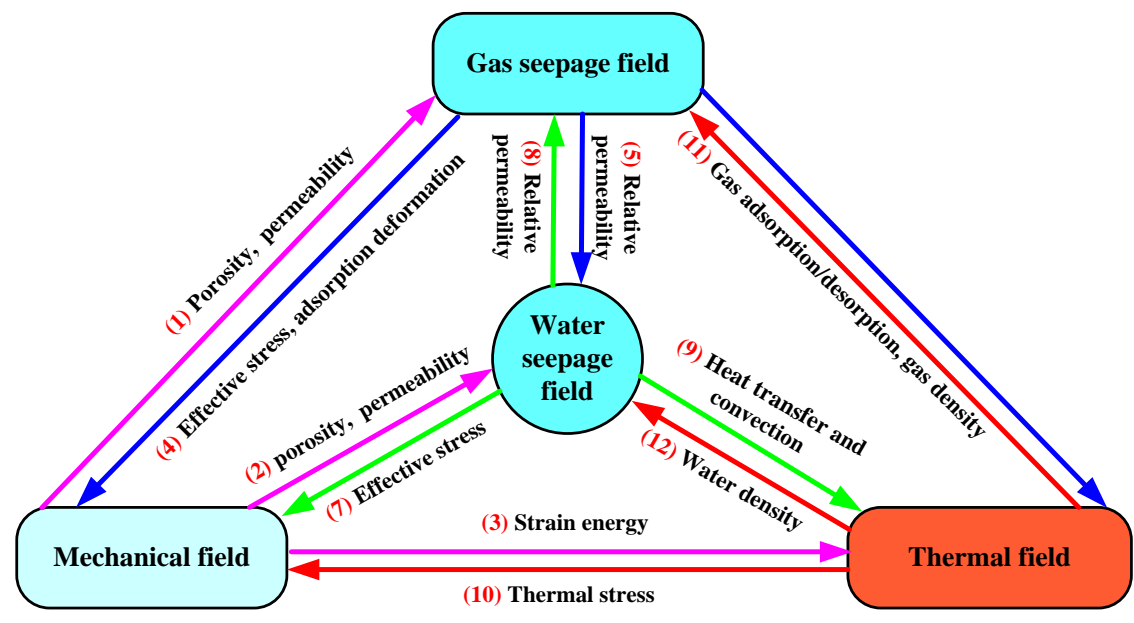

